IZA DP No. 9116

The Heterogeneous Impact of Pension Income on Elderly Living Arrangements:

Evidence from China's New Rural Pension Scheme

Lingguo Cheng

Hong Liu

Ye Zhang

Zhong Zhao

June 2015 


\title{
The Heterogeneous Impact of Pension Income on Elderly Living Arrangements: Evidence from China's New Rural Pension Scheme
}

\author{
Lingguo Cheng \\ Shanghai University of Finance and Economics \\ Hong Liu \\ Central University of Finance and Economics
}

Ye Zhang

Nanjing University

Zhong Zhao

Renmin University of China and IZA

Discussion Paper No. 9116

June 2015

IZA
P.O. Box 7240
53072 Bonn
Germany

Phone: +49-228-3894-0

Fax: +49-228-3894-180

E-mail: iza@iza.org

\begin{abstract}
Any opinions expressed here are those of the author(s) and not those of IZA. Research published in this series may include views on policy, but the institute itself takes no institutional policy positions. The IZA research network is committed to the IZA Guiding Principles of Research Integrity.

The Institute for the Study of Labor (IZA) in Bonn is a local and virtual international research center and a place of communication between science, politics and business. IZA is an independent nonprofit organization supported by Deutsche Post Foundation. The center is associated with the University of Bonn and offers a stimulating research environment through its international network, workshops and conferences, data service, project support, research visits and doctoral program. IZA engages in (i) original and internationally competitive research in all fields of labor economics, (ii) development of policy concepts, and (iii) dissemination of research results and concepts to the interested public.
\end{abstract}

IZA Discussion Papers often represent preliminary work and are circulated to encourage discussion. Citation of such a paper should account for its provisional character. A revised version may be available directly from the author. 


\section{ABSTRACT \\ The Heterogeneous Impact of Pension Income on Elderly Living Arrangements: Evidence from China's New Rural Pension Scheme}

This paper investigates the impact of pension income on living arrangements of the elderly. Taking advantage of a unique opportunity due to the recent establishment and expansion of the social pension system in rural China, we explicitly address the endogeneity of pension status and income through a fixed-effect model with instrumental variable approach by exploiting exogenous time variation in the program implementation at county level. We find an overall positive effect of pension income on independent living as well as considerable heterogeneity. The elderly with easy access to their adult children, possessing higher financial capacity, in less long-term care and psychological need, and having more education are more likely to live independently after receiving pension income. Our results confirm that independent living is a normal good, but highlight that living arrangement is multidimensional in rural China.

JEL Classification: J12, H55, I38

Keywords: $\quad$ pension income, living arrangements, heterogeneity, China

Corresponding author:

Hong Liu

Central University of Finance and Economics

39 Xueyuan Nan Road

Beijing 100081

China

E-mail: liuhong@cufe.edu.cn

\footnotetext{
"We would like to express appreciation for comments from seminar participants at Central University of Finance and Economics and Renmin University of China. This study was supported by NIH R01 grant (5R01-AG023627), the Natural Science Foundation of China (Grant No. 71110107025, No. 71173227, No. 71203244, and No. 71233001), the National Social Science Fund of China (Grant No. 13CJY028), Program for New Century Excellent Talents in University (Grant No. NCET-12-0993), and Training Program for Major Fundamental Research of Central University of Finance and Economics (Grant No. 14ZZD001).
} 


\section{Introduction}

As a result of declines in fertility and mortality, population aging is becoming a major public policy concern for transition and developing countries, which have been lacking strong formal social support systems. Many developing countries are currently attempting to initiate or to expand social pension programs in order to improve the well-being of the growing elderly population.

China has the largest elderly population in the world. According to the most recent census, in 2010 there were 178 million people aged over 60 and 119 million over 65 , accounting for $13.3 \%$ and $8.9 \%$ of total population in China, respectively; about 60 percent of them live in rural areas. Despite China's high economic growth during the past three decades, the rural elderly remain poorer and more vulnerable than the urban elderly, due to the large rural-urban disparity, low savings, lack of pension support, and heavy reliance on family support (Cai et al., 2012). The estimated poverty rate for rural elderly was around 20 percent in 2006, much higher than that for urban elderly in China (Cai et al., 2009; Park et al., 2012).

To improve the welfare of the rural elderly, in 2009 the Chinese government launched the New Rural Pension Scheme (NRPS) in China. It was first implemented in 320 pilot rural counties in 2009, was then expanded to 838 counties (approximately $40 \%$ of all rural counties) in 2010 , and covered nearly all rural counties by $2012 .^{1}$ By the end of 2011, about 89 million rural elderly had received pension payments under the NRPS. In this paper, we examine the effect of NRPS participation and pension income from the NRPS on living arrangements of the Chinese elderly.

Living arrangements have long been regarded as a key dimension of quality of life and an important indicator of long-term care demand in old age (Pezzin et al., 1996; Hoerger et al., 1996; Dostie and Léger, 2005; Bethencourt and Ríos-Rull, 2009). This importance has led to a growing body of research on the effect of income or social security payments on living arrangements of the elderly. The existing empirical literatures, primarily focusing on developed countries, have mixed results. Studies on

\footnotetext{
${ }^{1}$ China has 2,856 county-level administrative areas, and among them, 2,003 are rural counties. The rests are county-level districts under the jurisdiction of municipalities, which are mainly urban areas.
} 
the United States show constantly that the increase in pension income has led to a rise in independent living by the elderly, suggesting that independence is a normal good (Costa, 1997 and 1999; McGarry and Schoeni, 2000; Engelhardt et al., 2005). In contrast, using a sample of Italian parents aged 37 to 74, Manacorda and Moretti (2006) find that higher levels of parental income increase the probability of cohabitation, implying that coresidence is a normal good for Italian parents. There are few studies on developing countries; one exception is Edmonds et al. (2005). They show that in South Africa pension income has not increased the likelihood of black elderly women's independent living, but resulted in changes in household composition.

Living arrangement is even more important in rural China: traditionally living with adult children is the primary mechanism through which the elderly obtain care and support (Benjamin et al., 2000). However, the increasing mass rural-to-urban migration and shrinking family size inevitably have eroded the foundation of the Chinese traditional intergenerational support system. For example, data from the China Health and Nutrition Survey show that the share of rural elderly living with adult children has dropped from nearly 70 percent in 1991 to just over 40 percent in 2006 (Cai et al., 2012).

Two recent studies have explored the elderly living arrangement in China, but find different results. Meng and Luo (2008) find that increases in pension income significantly raise the probability that the elderly will be independent, though their estimated income effect is much lower than those found in the United States. However, this study is on urban Chinese elderly. Lei et al. (2013) show that Chinese rural elderly with higher income are more likely to live with or live near their adult children. Neither study takes account of the endogeneity of pension participation and pension income. Such endogeneity could be important, and is likely to arise from reverse causality or unobserved heterogeneity, such as preference and unobserved lifetime earnings, correlated with pension status/income as well as with living arrangement.

Using panel data from the Chinese Longitudinal Healthy Longevity Survey, this study makes several contributions. First, taking advantage of a unique opportunity due 
to the recent establishment and expansion of the NRPS, we address the endogeneity of pension income by applying a fixed-effect model with instrumental variable correction by exploiting exogenous time variation in the NRPS implementation at the county level as our instrumental variable.

Second, Manacorda and Moretti (2006) suggest that parents may have different preferences for living arrangement across countries, which may help explain different findings for different countries in the literature. Our study highlights the multidimensionality of living arrangement and explicitly investigates the heterogeneity of the income effect on elderly living arrangements. Four possible aspects of heterogeneity are explored: geographic proximity of adult children, financial capacity, long-term care needs, and privacy concerns of the elderly. This is the main distinction of our paper from the existing literature.

We find that both the NRPS enrollment status and pension income have significantly increased the likelihood that the elderly live independently, suggesting that independent living is a normal good in rural China. Moreover, we find considerable heterogeneous effects. Our results show that the positive income effects of the NRPS are concentrated among the elderly with easy access to their adult children, better financial status, more education, and less long-term care and psychological needs. These findings provide evidence that independent living has multiple dimensions in China, and help to reconcile mixed findings in the literature.

Last but not least, there are few studies on the impact of the NRPS in rural China, mainly because it started only a few years ago, and the proper data is limited. This paper is one of the few studies to evaluate the impact of the NRPS on the welfare of the elderly in rural China. There is wide concern that the income from the NRPS may be too little to provide basic protection against poverty in old age. Our study sheds light on this issue and adds to the limited literature on the evaluation of social pension programs in developing and transition countries (Kakwani and Kalanidhi, 2005; Palacios and Oleksiy, 2006; Barrientos, 2009). Given that many countries are becoming aging societies, our study has important policy relevancy to other countries as well. 
The remainder of the paper is organized as follows. Section 2 provides background on the NRPS in China. Section 3 presents a simple conceptual framework, which allows us to conceptualize heterogeneous income effects on elderly living arrangements. Section 4 outlines our estimation strategy. In section 5 we describe the data and variables used in the analysis. Section 6 gives the main results, including validating the assumptions of our empirical strategy. Section 7 deals with panel attrition. Section 8 concludes the paper.

\section{Rural Pension System in China}

During the 1950s through the 1970s, in view of its urban-oriented development strategy and state-owned economy, China's first formal pension scheme mainly covered urban workers, while the rural residents could only depend on their land and families for old-age support (Shi, 2006). In the 1990s, the government attempted to establish some form of rural pension insurance on a pilot basis in some well-off counties, which was financed primarily by individual contributions. Partly due to inadequate subsidies from the government, this pilot pension scheme had inadequate funding, and collapsed in most pilot areas (Li, 2007).

It was estimated that over 90 percent of the 100 million elderly living in rural areas did not have any pension coverage in 2007 (Shen and Williamson, 2010). Meanwhile, the traditional family support to the rural elderly has faced great challenges due to the reduced family size associated with the family planning policy since the late 1970 s and the increase of rural-to-urban migration since the late 1980s (Giles et al., 2010).

In order to provide a basic social safety net for rural residents, in 2009 the Chinese government launched a nationwide project known as the New Rural Pension Scheme (NRPS). The scheme began as a pilot in 320 rural counties (about 15 percent of all rural counties), selected by central and provincial governments. In 2010, 518 new counties were added for the second batch of the pilot. The scheme was expanded to 1,902 counties by 2011 and to nationwide by 2,012 .

The NRPS is a voluntary social pension program consisting of a basic pension 
and an individual pension account. All rural residents aged 16 or above who are not in school and not enrolled in an urban pension scheme are eligible to participate.

Different from the previous pilot one, the NRPS is financed by a combination of individual contributions and subsidies shared between central and local governments. Financial support from rural collectives is encouraged but not mandated. Central government bears the full cost of the non-contributory element for the relatively poor central and western regions, and half the cost for eastern regions. Individual contributions, ranging from 100 to 500 Chinese yuan per year at the choice of the enrollee, $^{2}$ and a partial matched contribution by central or local governments, which is at least 30 Chinese yuan per year and is larger for larger individual contributions, are paid into individual accounts and accumulated at a one-year deposit interest rate. The NRPS is currently pooling at the county level, and is targeted at pooling at the provincial level when feasible.

Participants who have contributed for 15 years will be eligible for a pension at age 60. Those aged 45-59 can contribute during their working lives or pay a lump sum to cover any shortfall in the vesting period of 15 years of contribution. At the time the program is introduced, despite paying no contribution to the NRPS, those older people aged 60 and over can directly receive the basic pension benefit as long as their adult children participate in the program. ${ }^{3}$

The NRPS benefits include a basic flat rate pension and a monthly payment from the individual account. The monthly payment from the individual account is equal to the accumulated amount in the individual account divided by $139 .^{4}$ The level of the basic flat rate pension varies across regions, with a minimum value of 55 Chinese yuan per month, which is financed mainly by the central government. Local governments are encouraged to make additional contributions at their discretion. For example, the basic pension benefit of rural residents in Beijing was about 280 Chinese

\footnotetext{
21 US dollar is about 6.2 Chinese yuan.

${ }^{3}$ In practice, the requirement for the participation of the children has been dropped gradually in many areas. In some areas, the elderly aged 60 and over are also allowed to pay a lump sum to cover shortfall on vesting contributions, which may or may not be subsidized, depending on local policies.

${ }^{4}$ As the life expectancy in 2009 was 71.5 years in China, the average duration of benefits is 11.5 years, or 139 months, for a 60 -year old individual.
} 
yuan per month in the starting year, due to additional contributions from local government. However, in some regions, the old people only receive a basic monthly pension of 55 Chinese yuan, which equals 13.9 percent of the 2008 average per capita net income in rural China. ${ }^{5}$ Moreover, 55 Chinese yuan per month is close to the 2008 poverty threshold set at 783 Chinese yuan per year by the Chinese government (Shen and Williamson, 2010), and is about 27.5 percent of the average monthly living expenses among Chinese rural elderly (Zhang and Tang, 2008). Thus, the basic pension benefit of the NRPS is not adequate to maintain a minimum living standard, but can only help to pay for the basic necessities.

\section{Conceptual Framework}

The goal of our analysis is to examine the effect of the NRPS status and pension income on elderly living arrangement; particularly we pay attention to the heterogeneous income effects among the rural elderly and channels behind these heterogeneous effects.

In a standard collective decision-making model, the elderly parents and adult children jointly determine the elderly living arrangement (Hoerger et al., 1996). However, as we cannot observe the behavior of adult children, we model the decision of the elderly as a choice between living independently and cohabiting with adult children. ${ }^{6}$ For each type of living arrangement, we assume a separate utility function, which depends on consumption, autonomy, health care, household services, housing, interaction with children, etc. Following Costa (1997), we think of the elderly as solving a utility maximization problem in two stages. First, for each type of living arrangement, the elderly choose the optimal bundle of goods and services $\left(C^{*}\right)$, yielding an indirect utility. Second, the elderly choose the living arrangement which yields higher indirect utility.

Let $V^{i}\left(P^{i}, Y^{i} ; Z\right)$ and $V^{c}\left(P^{c}, Y^{c} ; Z\right)$ be the indirect utility functions corresponding to independent living and coresidence, respectively, as denoted by the

\footnotetext{
5 The replacement rate from the NRPS is lower than those in most OECD countries, which range from 20 to 40 percent and have a cross-country average of around 30 percent (Cai et al., 2012).

${ }^{6}$ We do not consider the choice to live in a nursing home, because it is rare in rural China.
} 
superscripts $(i$ and $c$ ), where $P$ indicates the price of the bundle; $Y$ is income, which may include both the income of the elderly and the income of their adult children in an altruistic model, or just the income of the elderly in an exchange model (Cox, 1987; Costa, 1997); $Z$ represents a vector of exogenous variables affecting preferences, i.e., taste shifters such as education, health, age, and marital status. The elderly will decide to live independently if

$$
V^{i}\left(P^{i}, Y^{i} ; Z\right)>V^{c}\left(P^{c}, Y^{c} ; Z\right)
$$

An increase in pension income may expand the budget constraint of the elderly, and affects the optimal choice for the living arrangement. Such changes in elderly living arrangement associated with income may reveal their preferences towards independence or coresidence (Edmonds et al., 2005). If independent living is normal, an increase in pension income will lead to an increase in the demand for independent living.

Besides the income effect, other factors can also influence the living arrangement as well as the relationship between income and living arrangement. The elderly may benefit from intergenerational coresidence through reduced unit living costs, more efficient informal care provided by adult children, and increased emotional comfort; while living independently is associated with a gain of privacy and increased independence. The tradeoff between independence and coresidence is subject to many factors, such as proximity to their adult children, financial capacity, long-term care needs, and the privacy preference of the elderly. Therefore, based on equation (1), we hypothesize that the pension effects may operate in a heterogeneous manner. We consider four possible sources of heterogeneity.

The first source is access to their adult children. Adult children are the main providers of unpaid informal care and household services for the elderly in addition to themselves and their spouses. When the elderly and informal caregivers live in the same household, the shadow price of informal caregiving time is lower due to reduced travel costs; unit living costs are also reduced due to economies of scale (i.e., $\left.P^{c}<P^{i}\right)$. The price vector for independent living $\left(P^{i}\right)$ is not fixed, but is a function 
of the elderly's access to their adult children, e.g., the geographic proximity of their adult children. The closer adult children are, the smaller the price vector is. When pension income is small, as in the case of the NRPS, the decision of the elderly to live independently might be more sensitive when they have adult children living nearby.

The second source is financial capacity and financial concern. The most preferred bundle of goods and services, denoted by $C^{*}$, can be purchased in the market, provided by adult children, or provided by the elderly themselves and their spouses. As pension income rises, the elderly will replace less costly alternatives with higher-priced ones. For example, the elderly may transfer resources to adult children for more goods and services otherwise provided by themselves, leading to an increase in cohabitation; or they may substitute away from goods or services provided by themselves or adult children, choosing market alternatives, which may be associated with an increase in independent living. As pension income of the elderly increases, which income effect is dominant may depend on the family's initial financial resources $(Y)$.

The third source is long-term care needs, mainly based on the physical and mental health status of the elderly (included in $Z$ ). Because China's long-term care system is underdeveloped, especially in rural areas, most long-term care is provided informally by unpaid spouses, adult children, or hired help. The elderly with more need for informal care will gain more utility from coresidence. As the income of the elderly increases, potential substitutions among these three sources of informal care (spouse, adult children, and hired help) lead to different choices of optimal consumption bundle and optimal living arrangement. Thus, the income effect on the elderly living arrangement may vary with health status and marital status (related to the source of informal care).

The last source is the preference for privacy, also included in $Z$. People have a desire for privacy and autonomy, other things being equal (Ermisch, 1981; Hoerger et al., 1996; Engelhardt et al., 2005). Elderly living in an intergenerational household may not only lose their autonomy to some degree in their choice of consumption bundles, but also suffer a loss of privacy due to limited living space. We hypothesize 
that the more educated the elderly are, the stronger is their preference for privacy and autonomy.

\section{Empirical Strategy}

To investigate the impact of pension income from the NRPS on living arrangements of the elderly, we estimate the following model using two-wave panel data:

$$
Y_{i t}=\beta_{0}+\beta_{1} \text { Pension }_{i t}+\beta_{2} X_{i t}+\beta_{3} v_{t}+c_{i}+\varepsilon_{i t}
$$

where $i$ and $t$ index individuals and year, respectively. $Y_{i t}$ denotes the living arrangement choice of the elderly $i$ in period $t$. Pension $i t$ has two measures: one is an indicator variable for whether the elderly $i$ participated in the NRPS at time $t$, and the other is a continuous variable measuring pension benefits the elderly $i$ received at time $t$. The vector $X_{i t}$ contains observed household and individual characteristics, while $c_{i}$ represents an unobserved household or individual characteristic that is fixed across $t$. $v_{t}$ is a wave effect. Finally, $\varepsilon_{i t}$ is a disturbance term.

The coefficient $\beta_{1}$ of Pension $_{i t}$ is our main interest. However, pension income from the NRPS can be endogenous, since the enrollment in the NRPS is voluntary, and the OLS estimates may suffer from selection bias. The rural elderly in our sample (aged 65 to 84 years) can directly receive basic pension benefits without contributing, conditional on the enrollment of their adult children, and may be allowed to pay a lump sum to cover shortfalls in vesting contributions in some places. The pensioners and non-pensioners may differ in their adult children's unobserved behavior, household preference, family ideology, etc.

For example, the elderly's living arrangements may be determined partly by migration decisions of their adult children, which are unobserved in our data. In particular, when the migration probability of the adult children is high, it will be natural to observe a high proportion of independent living and a low take-up rate of the NRPS by the elderly, due to the low motivation of their adult children to enroll in 
a local pension program. Moreover, filial piety has been a central value of traditional Chinese culture and has continued to help maintain family care for the elderly despite substantial economic development and social change. Adult children with strong belief in filial piety may be more likely to enroll their parents in the NRPS; meanwhile, they may tend to live with their parents to provide family support. In both scenarios, the OLS estimate will underestimate the income effect on independent living because of bias from omitted variables.

We deal with the endogeneity of Pension $i t$ in the following ways. First, we control for a rich set of individual and household characteristics, including family financial resources, characteristics of children, health, and demographic variables. A wave dummy is also included to control for any non-parametric change of elderly living arrangement through time. Second, we control for time-invariant unobserved heterogeneity at the county (program), household, and individual levels, using fixed effects (FE) specifications. Third, we use instrumental variable techniques to estimate the FE model and to correct for the remaining bias due to time-variant unobservables. Thus, our main empirical strategy is FE with instrumental variable correction (FE-IV).

We use the exogenous time variation of the NRPS implementation at the county level as the instrument for the individual's enrollment status and pension income. A continuous variable is created to measure the length of program duration in a county at time of survey. The underlying idea is that the timing of starting the NRPS at the county level was mainly decided by the central and provincial governments, and should be uncorrelated with an individual's choice of living arrangement and his unobserved characteristics. As the NRPS currently operates on a local basis, only registered rural residents in the project counties are eligible for the program, so migration for the NRPS is not an issue. Thus, individual pension status and pension income should be highly correlated with the introduction and the duration of the NRPS at the county level. In fact, measured in wave 2011/12, the NRPS enrollment rate among the rural elderly was 39 percent, 20 percent, and 11 percent for counties starting the NRPS in 2009, 2010, and 2011 in our sample, respectively. Though we 
have only one instrument and the model is just identified, we conduct several empirical checks on the validity of the identification assumptions of our FE-IV model in section 6.

\section{Data and Variables}

\subsection{The Chinese Longitudinal Healthy Longevity Survey}

Our data come from the Chinese Longitudinal Healthy Longevity Survey (CLHLS) administered by the Center for Healthy Aging and Development Studies at Peking University and co-sponsored by the National Institute on Aging of the United States. This survey was first conducted in 1998 with a focus on the oldest-old, aged 80 and above. The follow-up waves, with replacement sample for deceased elderly, were conducted in 2000, 2002, 2005, 2008/09, and 2011/12. ${ }^{7}$ Beginning in 2002, younger elderly aged 65-79 have been added to the survey. The CLHLS randomly selected half of the counties and cities in 22 of the 31 provinces in China. ${ }^{8}$ The survey combines an in-house interview and a basic physical examination. It contains extensive information on individual and household characteristics: living arrangements, social and family support, socioeconomic conditions, health status, disability measurement, demographic variables, etc. The CLHLS is a high-quality data set with low non-response rate. Full details of the sampling design, response rates, and data quality assessment are described in Zeng et al. (2001), Zeng and Gu (2008), and $\mathrm{Gu}(2008)$.

In this study, we mainly use the two most recent waves of the CLHLS data (2008/09 and 2011/12) and focus on the sample of the young-old (65-74) and the middle-old (75-84) in rural China. ${ }^{9}$ We exclude approximately 2.7 percent of respondents with missing values for pension status, 14.8 percent of respondents who

\footnotetext{
7 The CLHLS was conducted from May 2008 through April 2009 for wave 2008/09, and from July 2011 through September 2012 for wave 2011/12.

${ }^{8}$ The sample provinces include 7 eastern provinces, 3 northeastern provinces, 8 central provinces, and 4 western provinces, which host approximately $85 \%$ of China's total population.

${ }^{9}$ We do not include the oldest-old sample in the main analysis, because the oldest-old population is not the focus of the existing literature (besides, there are few oldest-old observations in many studies), and their living arrangement may be dictated by health care need instead of economic concerns. Thus, we only use the oldest-old sample as an additional check for the channel of long-term care needs underlying the income effects on elderly living arrangement in section 6.4.
} 
had a retirement pension, private pension, or other social pension during the period 2008/09-2011/12, and less than 1 percent of respondents residing in elderly centers or nursing homes. These restrictions result in a sample of 2,627 rural respondents who (or whose close family members) had been interviewed in wave 2008/09. Of these, 485 respondents (18.5 percent) died before the 2011/12 survey, and 316 (12 percent) were lost to follow-up (we return to the attrition issues in Section 7). The remaining 1,826 respondents form the main sample for our analysis. This has given us a balanced panel of 3,652 person-year observations in 535 counties.

\subsection{Dependent variable}

Following the previous literature, we define dependent variables measuring whether the respondent is living independently or with others. Based on the residential setting and household composition of the respondents, we consider the elderly living alone or living with a spouse to be living independently; we also treat the elderly who live with parents/in-laws or with children under age $15^{10}$ as living independently. Reference persons living in an extended family, such as living with adult children, siblings, relatives, or other adults, are defined as coresidents. ${ }^{11}$

Figure 1 presents the change of living arrangement of rural elderly based on the CLHLS data from 1998 to 2011/12 with adjustment of the sampling weights. Consistent with the literature (Cai et al., 2012), independent living among rural elderly had increased for the young-old (age 65-74), the middle-old (age 75-84), and the oldest-old (age 85 and above). Over half of the rural elderly aged 65-84 lived independently in wave 2011/12. As age increases, the elderly were more likely to reside with adult children or others.

\section{-----Figure 1-------}

\subsection{The NRPS status and individual pension income}

\footnotetext{
${ }^{10}$ Among those we classify as independent living, 1 person-year observations $(0.03$ percent of the study sample) lived with parents/in-laws, and 19 person-year observations $(0.52$ percent of the study sample) lived with children under age 15 .

${ }^{11}$ We exclude institutionalized individuals because they account for less than 1 percent of the study sample. The results are very similar when we include them, no matter whether they are classified as living with others or as living independently.
} 
The key independent variables include a dichotomous measure indicating individual participation in the NRPS and a continuous variable measuring the NRPS benefit. The CLHLS did not gather the information on the NRPS at the individual or county levels directly, but asked the respondents whether they were covered by a retirement pension, social pension, or private pension in waves 2008/09 and 2011/12. As the NRPS was implemented in rural areas beginning in 2009, those respondents who reported no social pension in wave 2008/09 but having social pension in wave 2011/12 are considered as the NRPS pensioners. In wave 2011/12, 419 respondents (about 23 percent) participated in the NRPS, and received an average 130 Chinese yuan pension income per month.

We use an instrumental variable approach to address the endogeneity of pension income associated with the NRPS enrollment decision. Since we know the exact location information for the sample counties, combined with the lists of the NRPS pilot counties authorized by China's central and provincial governments in 2009 and 2010, we are able to determine whether and when each sample county in the CLHLS implemented the NRPS. Among the 535 sample counties, 77 (14 percent) belong to the first-wave pilot counties that implemented the program in 2009; 127 (24 percent) belong to the second-wave pilot counties in $2010 ;^{12}$ and the remaining 331 counties were gradually exposed to the program in 2011. Thus, we construct a continuous variable measuring the duration of NRPS implementation at county level at time of survey, using interview dates of the respondents from the CLHLS and dates of program initiation from the pilot lists. ${ }^{13}$ By this construction, this instrument is exogenous and independent of other factors that affect the living arrangement of the elderly at the individual and the household level.

\subsection{Other explanatory variables and descriptive statistics}

We control for other factors that may affect the living arrangement of the elderly, such as family financial resources, characteristics of the children, health, and

\footnotetext{
12 The exposed rates are consistent with national data, which were $15 \%$ in 2009 and $26 \%$ in 2010.

${ }^{13}$ We do not know the exact dates of program initiation for each county. As the government made announcements about the first two waves of pilots on 31st September 2009 and 30th September 2010, respectively, we assume that it was October 2009 for the first pilot counties, October 2010 for the second pilot counties. The third wave of pilots rolled out in July 2011.
} 
socio-demographic variables of the elderly.

To investigate the impact of kin availability on independent living, we include the number of adult children alive at interview.

For the elderly, we include two binary variables to measure their financial resources: one indicator for financial independence, and another indicator for homeownership.

Health variables include instrumented activities of daily living (IADL) and cognitive functions. The survey questions about IADL and cognitive functions are based on an international standard questionnaire adapted to the Chinese culture and social context with careful pilot testing (Zeng et al., 2002). Specifically, we use a binary variable indicating whether the respondent can finish eight daily activities without assistance, including visiting the neighbors, doing shopping, cooking a meal, washing clothes, walking continuously for 1 kilometer, lifting a weight of 5 kilograms, continuously crouching and standing up three times, and taking public transportation. It is coded 1 if no restriction in these activities was reported and 0 otherwise. Following the literature (Crum et al., 1993; Folstein et al., 1975), we use the Mini-Mental State Examination (MMSE) to detect cognitive impairment of the elderly. The MMSE in the CLHLS includes five dimensions: orientation, reaction, calculation, recall, and language, with a total score ranging from 0 to 30. A score of 24 and lower indicates some degree of cognitive impairment.

Other variables of the elderly include years of schooling, occupational category before age 60 ( 1 = had a white-collar job, i.e., professional, managerial, or administrative), age, age squared, gender, ethnicity $(1=$ Han Chinese; $0=$ ethnic minorities $),{ }^{14}$ and marital status $(1=$ married $)$.

\section{-----Table 1-------}

In Table 1, among the comparison group who had no pension in either wave, the proportion living independently declined from 55 percent in wave 2008/09 to 50.9

\footnotetext{
${ }^{14}$ Han Chinese is the majority ethnic group in China, and accounts for more than $90 \%$ of the total population.
} 
percent in wave 2011/12, partly due to aging. However, the percentage of the NRPS pensioners who lived independently has increased slightly, from 51.8 percent to 52.7 percent, during the study period.

Standard $t$-tests indicate that there was no significant difference in living arrangement and individual/household characteristics between the pensioners and non-pensioners in wave 2008/09, except that the pensioners were more likely to be Han Chinese, and to have a white-collar job before age 60. In addition, in wave 2011/12 the elderly pensioners were more likely to have better health status in terms of IADL.

\section{Main Results}

\subsection{First stage of the FE-IV model}

As noted above, we estimate equation (2) and address the endogeneity of the NRPS enrollment and pension income using the FE-IV approach.

Table 2 shows the first-stage results from the OLS estimation using cross-sectional data from wave 2011/12 (columns (1) and (3)) as well as the FE estimation using the panel sample (columns (2) and (4)). Robust standard errors are clustered at the individual level.

-----Table 2-------

For all specifications, the coefficients of the NRPS duration at county level are positive and significant at the 1 percent level. This suggests strong correlations between the program duration and individual pension status and income, with a partial $F$-statistic over 390 in the FE estimations. For one more month of implementation, the likelihood that an elderly person participates in the NRPS increases by 2.1 percentage points, and the individual pension incomes increase by 9.4 percent.

Moreover, we find that the elderly who were younger were more likely to enroll in the NRPS. The OLS estimates show that health status and being Han Chinese are both positively associated with pension income from the NRPS.

\subsection{Results for the whole sample}

Table 3 reports our results for the whole sample. Column (1) presents the FE 
estimate of the intent-to-treat effect of the NRPS. A half-year duration of the NRPS implementation increases the probability of independent living significantly, by 2.4 percentage points.

In columns (2) and (4), the FE results without instrumenting show that overall, both the NRPS enrollment and pension income have positive but insignificant effects on the probability of living independently for the rural elderly. After correcting for the endogeneity bias using the FE-IV approach, the estimates of the NRPS enrollment in column (3) and pension income in column (5) are both positive and significant at the $1 \%$ level, and of larger magnitude than the FE estimates. ${ }^{15}$ This shows that participation in the NRPS has significantly increased the likelihood of the pensioners living independently, by 17.8 percentage points. The coefficient on the log pension income is 0.041 , implying that a 100 percent increase in the monthly pension income of the elderly raises the likelihood of independent living by 4.1 percentage points. Consistent with our discussion in section 4, the downward bias is substantial in the FE estimates that fail to address the endogeneity of the NRPS status and pension income. Our findings are consistent with previous literatures on the United States (e.g., Engelhardt et al., 2005; Costa, 1997 and 1999) or urban China (Meng and Luo, 2008), suggesting that independent living is a normal good in rural China.

To facilitate the comparison between our results and the ones in the literature, we obtain an elasticity of coresidence with respect to pension income of -0.087 $(=[-0.041] /[1-0.528])$ for rural elderly when evaluated at the sample mean. This is larger than those of Meng and Luo (2008); they find an elasticity of -0.018 to -0.037 for urban elderly in China. The difference may not reflect that the rural elderly respond more elastically to pension income in their living arrangement decisions, but instead result from the downward bias in the estimates of Meng and Luo (2008), which does not address the endogeneity problem.

Moreover, our estimated elasticity of coresidence with respect to pensions is

\footnotetext{
${ }^{15}$ Our FE-IV estimate of the coefficient $\beta_{1}$ identifies the average causal effect of pension income for a subgroup of compliers, viz., those rural elderly who are induced by the NRPS implementation to change their pension status or pension income. Thus, we interpret the FE-IV estimate as a local average treatment effect of pension income (Imbens and Angrist, 1994).
} 
much lower than those found in the literature on the United States, e.g., an elasticity of -0.77 in Costa (1997), and an elasticity of -0.4 in Engelhardt et al. (2005). One explanation is that the pension income and the replacement rate from the NRPS are very low compared to social security in the United States. The other potential explanation is that living arrangement is multidimensional in China, and we will discuss that in detail in a later subsection.

\subsection{Validity of the Identification Assumption}

To establish the causal relationship, our key identification assumption is that the implementation timing of the NRPS at the county level is independent of the time-varying factors in the error term of equation (2). This is a plausible assumption, since the selection of pilot counties and the exact time of program initiation are both beyond the control of individuals. However, there are still possibilities that the pilot and non-pilot counties differ in some unobserved and time-varying characteristics other than the NRPS, which are correlated with living arrangement of the elderly. Thus we assess the validity of our empirical strategy in two ways.

First, in order for our FE-IV approach to be valid, this would require that changes in elderly living arrangement should not be systematically related to other time-varying omitted factors. For example, pilot and non-pilot counties may be different with respect to return migration after the global financial crisis in 2008 , or to formal elderly care systems. To check this, we use the retired sample that has retirement pensions. Since the retired sample was not ineligible for the NRPS but shared the same county-level heterogeneity with our main study sample, we expect that the NRPS program at county level would not have any effects on them. In columns (1) and (2) of Table 4, the results show that the estimates are statistically insignificant for the retired sample in both OLS and FE regressions. This falsification test suggests that there is no other unobserved county-level heterogeneity that has been changing over this study period and also associated with elderly living arrangement in rural China.

-----Table 4-------

Second, it could also be the case that the rural elderly population targeted by the 
NRPS in the pilot counties has had different living-arrangement dynamics from those in the non-pilot counties before the introduction of the NRPS. To test for this, we examine whether the elderly study sample in the 2009-2010 pilot counties and non-pilot counties had different living arrangements before the NRPS, which started in 2009. In column (3) of Table 4, the OLS estimates based on the 2008/09 data are insignificant and have the wrong signs. In column (4), we carry out a placebo test and assume that the (nonexistent) NRPS had been introduced in pilot counties during 2005-2008, and obtain the FE estimates of the NRPS effects using the 2005 and 2008/09 waves of data. The results also show no significant differences in living arrangement between the elderly in pilot and non-pilot counties during the two waves 2005 and 2008/09.

Moreover, in Table 2, our IV passes the weak instrument test with high significance level. Although we have to admit that the validity of the identification assumption is fundamentally untestable, the above two experiments as well as the institutional setup of the NRPS implementation provide strong evidence for the validity of our FE-IV approach.

\subsection{Heterogeneous Effects and Channels}

Given the high degree of heterogeneity within the elderly rural population in China, to understand better the linkage between pension and living arrangement, it may not be sufficient to look only at the overall living arrangement pattern. Following our conceptual framework, we investigate different mechanisms underlying the decisions about elderly living arrangements by looking at heterogeneous effects with respect to proximity of the adult children, financial capacity, long-term care needs, and privacy concerns of the elderly. To do so, we divide the sample into different subgroups according to the baseline characteristics. Each cell in Table 5 represents a different regression and reports the parameter estimate for individual NRPS enrollment (in columns (1) and (2)) or pension income (in columns (3) and (4)).

-----Table 5-------

Cai et al. (2012) show that more than half of the rural elderly who lived independently had one or more adult children residing in the same village in 2003. 
Therefore, in Panel 1, we examine the differential effects of pension income with respect to the presence of adult children living nearby in the baseline wave. ${ }^{16}$ The rationale is that the decision of the elderly to live independently might be more sensitive to the pension income when they have easy access to their adult children. Focusing on the elderly with their adult children in the same village, we find that the results are stronger than those in Table 3; the FE-IV estimates on the NRPS enrollment and pension income are 0.213 and 0.049 , both significant at the $1 \%$ level and of larger magnitude than the estimates for the whole sample. As a further check, we also report the results for the elderly without nonresident adult children in the same village. Consistent with our priors, the estimated coefficients on the NRPS enrollment or pension income are either insignificant or only marginally significant in FE-IV estimations.

Taken together, the findings in Panel 1 of Table 5 show that access to adult children is an important factor for the elderly living arrangement. Most of the income effect from the NRPS on the independence of rural elderly was concentrated among those with adult children still residing in the same village. Our overall findings about the increase in independent living among the pensioners in Table 3 do not necessarily represent a collapse of family-based support for them, since the children in the same village can still provide care for their parents (Lei et al., 2013).

In Panels 2 and 3, we examine subgroups by economic independence and homeownership of the elderly. Both the FE estimates and the FE-IV estimates indicate an insignificant effect of pension income on living arrangements for the elderly without economic independence or having no homeownership. However, for the elderly who are economically independent or own their homes, we find significant positive effects, and the estimates imply that the elasticity of coresidence with respect to pension income is around -0.15 . A possible explanation is that due to the low level of pension benefits, the rural elderly can hardly rely on the NRPS income alone to

\footnotetext{
${ }^{16}$ In Panel 1, we divide the sample into two groups: with or without non-resident adult children in the same village, based on the information in wave 2008/09. It should be noted that both groups include those elderly with shared living arrangement in 2008/09, so the sum of sample sizes for the two groups is bigger than our full sample size.
} 
meet their preference of living arrangement. In situations where the elderly have more financial capacity, additional income from the NRPS will be more likely to induce them to live independently. Our finding provides evidence for the S-shaped relationship between independent living and income suggested in the literature (Michael et al., 1980; Costa, 1997), implying that the impact of an income rise on independent living may be small at low income levels, become sizable at higher income, and then decrease again. Our results belong to the first two parts of the S-shaped relationship.

Panel 4 shows the estimates by education group. For the educated elderly, the estimates indicate a significant increase in the likelihood of independent living, and the implied elasticity of coresidence to pension income is -0.186 . In contrast, we find an insignificant effect for the illiterate elderly. This finding is consistent with McGarry and Schoeni (2000), but appears inconsistent with Engelhardt et al. (2005), which finds that the positive effect of social security on independent living is concentrated among the lower-educated elderly in the United States. However, this should not be surprising. One possible explanation is that more educated people may have a stronger preference for privacy and autonomy, and thus display higher sensitivity of independent living arrangement to pension income. Another explanation is that the elderly population in rural China has much lower education level than those in the United States. Over half of the elderly sample had no education (defined as being illiterate in our study), while those with a high school education or less account for about 48 percent of the sample, classified as the less educated elderly by Engelhardt et al. (2005).

Panels 5 and 6 investigate the channel of long-term care needs by examining whether pension income has differential effects for the elderly by marital and health status. In Panel 5, the FE-IV results suggest that neither the NRPS enrollment nor the amount of pension benefits has significant effects on the likelihood of living independently for the widowed, while both have positive and significant effects for the married couples. We posit that married couples may be less reliant on adult children for informal care and social interaction than the widowed, and thus be more 
likely to live independently. This finding is inconsistent with the literature on the United States (Engelhardt et al., 2005; Costa, 1997). Those authors suggest that compared to married couples, widowed elderly have limited income sources, and their decisions with respect to living independently are more sensitive to pension income.

Now we turn to the estimates based on health status in Panel 6. For the group with no IADL limitation, the FE-IV estimates are positive and significant at the $1 \%$ level. Thus, for the elderly with no old-age disability, the likelihood of living independently has increased due to the NRPS take-up, and the estimated elasticity of coresidence to monthly pension benefits is -0.135 . However, among those with IADL limitation, we find that the estimates are negative and statistically insignificant, indicating no effect for the elderly with old-age disability.

The two different patterns reflect that the two channels of privacy concern and long-term care needs, through which the NRPS may affect elderly independent living, work in opposite directions. As there is no publicly provided home care in rural China, health status of the elderly is an important determinant of which of these two channels is likely to dominate.

As a further check, we also estimate the effect of pension income separately for the oldest-old (age 85 and above), the oldest-old without IADL limitation, and the oldest-old with IADL limitation.

In Table A2, we find that the estimates on the NRPS enrollment and pension income are all negative and statistically insignificant for the full sample of the oldest-old.

For the oldest-old without IADL limitation, the estimates are positive, but insignificant and economically small. This finding is different from that in Panel 6 in Table 5, suggesting that the income effect of the NRPS on privacy may be offset by its income effect on support and care from adult children, especially for those with high health needs. For those oldest-old with IADL limitation, the FE estimate shows a significant (at the 10 percent level) negative effect of pension income on the probability of independent living. It confirms our argument that while the dominant motive is to meet long-term care needs, the elderly may be more likely to choose 
coresidence as income increases.

\section{Panel Attrition}

A typical concern when using panel data is the attrition bias. As illustrated in the data section, given the age and frailty of the sample, 18.5 percent of the baseline sample died between surveys, and 12 percent were lost to follow-up in the 2011/12 survey. If attrition is not random, potential bias will arise.

Since the CLHLS collected some information, including social pension status, on the deceased persons before their death by interviewing a close family member of theirs in the 2011/12 survey, we can estimate the effects of the NRPS enrollment and pension income on living arrangement of the deceased sample. The NRPS take-up rate among the deceased sample in their last year of life was around 8.3 percent, which is much lower than that among the survivors. In Table 6, we report the OLS and IV estimates of equation (2) for the deceased sample. After controlling for individual characteristics and regional effects in wave 2008 as well as in their last year of life, we find that neither the NRPS enrollment nor pension income has a significant effect for the deceased sample.

-----Table 6-------

We additionally address the concern of potential attrition bias due to loss of follow-up in two ways. First, we test for selective attrition due to observables by investigating whether those lost to follow-up (i.e., attritors) differ in baseline outcome and characteristics from the follow-up sample (i.e., non-attritors). At first look, the descriptive statistics in Appendix Table A3 shows that the attritors are more likely to live independently than the non-attritors, and the two groups differ in several observed individual characteristics, such as age, homeownership, number of living children, and health status.

To formally test for attrition bias due to observables, we follow Becketti et al. (1988) and Ding and Lehrer (2010), and regress the baseline living arrangement on baseline individual characteristics and their interactions with a binary indicator for attrition, using the full sample of wave 2008/09: 


$$
Y_{i}=\delta_{0}+\delta_{1} \text { Attrition }_{i}+\delta_{2} \text { Attrition }_{i} \times X_{i}+\delta_{3} X_{i}+u_{i}
$$

where Attrition $_{i}$ is an indicator for loss to follow-up in wave 2011/12, and all other variables are defined as before. If $\delta_{1}$ and $\delta_{2}$ are jointly significant, selection on observables would be a problem. As shown in Table 7, we find that the estimated coefficients of the attrition indicator and its interaction terms are both individually and jointly insignificant. It implies that the attritors are not systematically different from the non-attritors in terms of their baseline characteristics and behavioral relationship, and suggests that attrition due to observables can be safely ignored. ${ }^{17}$

Moreover, in the FE framework of our main analysis, we also mitigate the concern regarding attrition due to unobservables that are time-invariant.

\section{Conclusion}

This paper has examined the impact of pension income from the NRPS on living arrangement of the elderly aged 65 to 84 in rural China. Taking advantage of the time variation of the NRPS implementation at county level, we employ the FE-IV approach to identify the causal effect of pension income, and conduct several empirical tests to check the validity of our identification assumptions.

The overall results suggest that the NRPS enrollment or pension income has significantly increased independent living of the rural elderly, suggesting that independent living is normal in China. A $100 \%$ increase in pension income would lead to a 4.1 percentage point increase in the likelihood of independent living, with an implied income elasticity of coresidence at -0.087 . This finding is striking, given the traditional norms regarding intergenerational coresidence in rural China and limited income from the NRPS. It highlights the important contribution of the rising income to the remarkable decline in coresidence with their adult children by both urban and rural elderly in China during the past three decades (Zeng and Wang, 2003; Benjamin et al., 2000; Palmer and Deng, 2008; Cai et al., 2012).

\footnotetext{
${ }^{17} \mathrm{Gu}$ (2008) state that the proportion lost to follow-up between waves of the CLHLS is low relative to those of some panel surveys of older persons conducted in Western countries (e.g., Mihelic and Crimmins, 1997).
} 
Further, we explore several mechanisms behind the impact of pension income on elderly living arrangement. In particular, we investigate the effect heterogeneity across a range of important observed characteristics, such as access to their adult children, financial status, education level, marital status, and health of the elderly. These heterogeneity findings provide evidence that independent living has multiple dimensions in China, and help to reconcile mixed findings in the literature.

We find that the positive income effects on independent living are concentrated among the elderly with easy access to their adult children, while there are modest or no effects for those without adult children living nearby. It suggests that the increase in independence among the pensioners does not represent a collapse of the family-based support tradition in rural China, since the nearby children can still easily provide informal care (Lei et al., 2013).

Our study finds that there is a significant positive effect of pension income for the elderly with economic independence or homeownership, but not for those without economic independence or homeownership. It indicates that financial capacity is an important factor behind the causal link between pension income and elderly living arrangement in China.

We also show that the educated elderly are more likely to live independently after they receive the NRPS income, while that is not the case for the illiterate elderly. We interpret this finding as evidence that privacy is a valued good, and educated people have stronger privacy preference.

Besides the privacy preference documented in the literature, our research suggests that long-term care need is another important dimension of elderly living arrangement. The results show that pension income positively and significantly increases the probability of independent living for the married elderly or those with better health status, but not for the widowed elderly or those with worse health status. This reflects the fact that family members, especially adult children, are the main providers of informal long-term care for the elderly in rural China.

Though our results do not speak directly to whether the NRPS would improve the welfare of the elderly or not through living arrangement, our study is an important 
step to such welfare evaluation. Despite general belief that intergenerational coresidence may provide old-age security for the elderly, the existing serious studies have produced mixed results. For example, Kochar (2000) shows that parents can benefit from coresidence by reducing labor supply, while Johar and Maruyama (2014) find that coresidence has a negative effect on health outcome of the elderly. More work should investigate this issue further, and the heterogeneity highlighted in this paper is probably one of the reasons for the mixed results.

Moreover, our findings provide important policy information on the development of elderly care systems and social pension programs in China as well as in other developing countries.

\section{References}

Barrientos, Armando. 2009. "Social Pensions in Low-Income Countries." In Closing the Coverage Gap: The Role of Social Pensions and Other Retirement Income Transfers, ed. Robert Holzmann, David Robalino, and Noriyuki Takayama, 73-84. Washington, DC: The World Bank.

Becketti, Sean, William Gould, Lee Lillard, and Finis Welch. 1988. "The Panel Study of Income Dynamics after Fourteen Years: An Evaluation." Journal of Labor Economics 6(4):472-92.

Benjamin, Dwayne, Loren Brandt, and Scott Rozelle. 2000. “Aging, Well-being, and Social Security in Rural Northern China." Population and Development Review 26:89-116.

Bethencourt Carlos, and José-Víctor Ríos-Rull. 2009. “On the Living Arrangements of Elderly Widows." International Economic Review 50(3):773-801.

Cai, Fang, John Giles, and Dewen Wang. 2009. "The Well-being of China's Rural Elderly.” Background Paper for East Asia Social Protection Team. Washington DC: World Bank.

Cai, Fang, John Giles, Philip O'Keefe, and Dewen Wang. 2012. The Elderly and Old Age Support in Rural China: Challenges and Prospects. Washington DC: World 
Bank.

Costa, Dora L. 1997. "Displacing the Family: Union Army Pensions and Elderly Living Arrangements.” Journal of Political Economy 105(6):1269-92.

Costa, Dora L. 1999. "A House of Her Own: Old Age Assistance and the Living Arrangements of Older Nonmarried Women." Journal of Public Economics 72(1):39-59.

Cox, Donald. 1987. "Motives for Private Income Transfers." Journal of Political Economy 95(3):508-46.

Crum, Rosa M., James C. Anthony, Susan S. Bassett, and Marshal F. Folstein. 1993. "Population-Based Norms for the Mini-Mental State Examination by Age and Educational Level." The Journal of the American Medical Association 269(18):2386-91.

Ding, Weili, and Steven F. Lehrer. 2010. "Estimating Treatment Effects from Contaminated Multiperiod Education Experiments: The Dynamic Impacts of Class Size Reductions." The Review of Economics and Statistics 92(1): 31-42.

Dostie, Benoit, and Pierre Thomas Léger. 2005. “The Living Arrangement Dynamics of Sick, Elderly Individuals.” Journal of Human Resources 40(4):989-1014.

Edmonds, Eric V., Kristin Mammen, Douglas L. Miller. 2005. "Rearranging the Family? Income Support and Elderly Living Arrangements in a Low Income Country." Journal of Human Resources, 40(1): 186-207.

Engelhardt, Gary V., Jonathan Gruber, and Cynthia D. Perry. 2005. "Social Security and Elderly Living Arrangements: Evidence from the Social Security Notch.” The Journal of Human Resources 40(2): 354-72.

Ermisch, John F. 1981. "An Economic Theory of Household Formation: Theory and Evidence from the General Household Survey." Scottish Journal of Political Economy 28(1): 1-19.

Folstein, Marshal F., Susan E. Folstein, and Paul R. McHugh. 1975. "Mini-Mental State: A Practical Method for Grading the Cognitive State of Patients for the Clinician.” Journal of Psychiatric Research 12(3):189-98.

Giles, John, Dewen Wang, and Changbao Zhao. 2010. "Can China's Rural Elderly 
Count on Support from Adult Children? Implications of Rural-to-Urban Migration.” Journal of Population Ageing 3 (3-4): 183-204.

Gu, Danan. 2008. "General Data Quality Assessment of the CLHLS.” In Healthy Longevity in China, ed. Zeng Yi, Dudley L. Poston, Denese Ashbaugh Vlosky and Danan Gu, 39-60. Dordrecht, the Neitherlands: Springer.

Hoerger, Thomas J, Gabriel A. Picone, and Frank A. Sloan. 1996. "Public Subsidies, Private Provision of Care and Living Arrangements of the Elderly." The Review of Economics and Statistics 78(3): 428-40.

Imbens, Guido W., and Joshua D. Angrist. 1994. "Identification and Estimation of Local Average Treatment Effects." Econometrica 62(2):467-75.

Johar, Meliyanni, and Shiko Maruyama. 2014. "Does Coresidence Improve an Elderly Parent's Health?” Journal of Applied Econometrics 29(6): 965-83.

Kakwani, Nanak, and Kalanidhi Subbarao. 2005. "Aging and Poverty in Africa and the Role of Social Pensions." Social Protection Discussion Paper 521. Washington, DC: The World Bank.

Kochar, Anjini. 2000. "Parental benefits from intergenerational coresidence: empirical evidence from rural Pakistan.” Journal of Political Economy 108(6): 1184-1209.

Lei, Xiaoyan, John Strauss, Meng Tian, and Yaohui Zhao. 2013. "Living Arrangement of the Elderly in China: Evidence from the CHARLS National Baseline.” Texas A\&M University. Unpublished.

Li, Bingqin. 2007. "Pension reform in China - who are left out?" In New Perspectives on China and Aging, ed. Ian G. Cook and Jason Powell, 29-48. New York: NOVA Science Publishers.

Little, Roderick J. A., and Donald B. Rubin. 1987. Statistical Analysis with Missing Data. New York: John Wiley \& Sons.

Manacorda, Marco, and Enrico Moretti. 2006. "Why Do Most Italian Youths Live with Their Parents? Intergenerational Transfers and Household Structure." Journal of the European Economic Association, 4(4): 800-29. 
McGarry, Kathleen, and Robert F. Schoeni. 2000. "Social Security, Economic Growth, and the Rise in Elderly Widows' Independence in the Twentieth Century." Demography 37(2): 221-36.

Meng, Xin, and Chuliang Luo. 2008. "What Determines Living Arrangements of the Elderly in Urban China.” In Inequality and Public Policy in China, ed. Björn A. Gustafsson, Shi Li and Terry Sicular, 267-86. Cambridge: Cambridge University Press.

Michael, Robert T., Victor R. Fuchs, and Sharon R. Scott. 1980. "Changes in the Propensity to Live Alone, 1950-1976.'’ Demography 17(1): 39-56.

Mihelic, Adrienne H., and Eileen M. Crimmins. 1997. "Loss to Follow-up in a Sample of Americans 70 Years of Age and Older: The LSOA 1984-1990.” The Journals of Gerontology Series B: Psychological Sciences and Social Sciences 52B(1): S37-48

Palacios, Robert, and Oleksiy Sluchynsky. 2006. "Social Pensions Part I: Their Role in the Overall Pension System." Social Protection Discussion Paper 36237. Washington, DC: World Bank.

Palmer, E., and Q Deng. 2008. "What Has Economic Transition Meant for the Well-being of the Elderly in China.” In Inequality and Public Policy in China, ed. Björn A. Gustafsson, Shi Li and Terry Sicular, 182-203. Cambridge: Cambridge University Press.

Park, Albert, Yan Shen, John Strauss, and Yaohui Zhao. 2012. "Relying on Whom? Poverty and Consumption Financing of China's Elderly." In Aging in Asia Findings from New and Emerging Data Initiatives, ed. James P. Smith and Malay Majmundar, Washington DC: National Academies Press.

Pezzin, Liliana E., Peter Kemper, and James Reschovsky. 1996. "Does Publicly Provided Home Care Substitute for Family Care? Experimental Evidence with Endogenous Living Arrangements." The Journal of Human Resources 31(3): $650-76$.

Shen, Ce, and John B. Williamson. 2010. “China’s New Rural Pension Scheme: Can it be Improved?" International Journal of Sociology and Social Policy 30(5/6): 
239-50.

Shi, Shih-Jiunn. 2006. "Left to Market and Family - Again? Ideas and the Development of the Rural Pension Policy in China." Social Policy and Administration 40(7):791-806.

Zeng, Yi, James W. Vaupel, Zhengyu Xiao, Chunyuan Zhang, and Yuzhi Liu. 2001. "The Healthy Longevity Survey and the Active Life Expectancy of the Oldest Old in China." Population: An English Selection 13(1): 95-116.

Zeng, Yi, James W. Vaupel, Zhengyu Xiao, Chunyuan Zhang, and Yuzhi Liu. 2002. "Sociodemographic and Health Profiles of the Oldest Old in China." Population and Development Review 28(2): 251-73.

Zeng, Yi. 2008. "Reliability of Age Reporting Among the Chinese Oldestold in the CLHLS Data Sets." In Healthy Longevity in China: Demographic, Socioeconomic, and Psychological Dimensions, edited by Zeng Yi, Dudley L. Poston, Denese Ashbaugh Vlosky, and Danan Gu, 61-78. Dordrecht, the Netherlands: Springer Netherlands.

Zeng, Yi, and Zhenglian Wang. 2003. "Dynamics of Family and Elderly Living Arrangements in China: New Lessons Learned from the 2000 census." China Review 3(2): 95-119.

Zhang, Wenjuan, and Dan Tang. 2008. “The New Rural Social Pension Insurance Programme of Baoji City.” Gerontology Research Institute of Renmin University. Unpublished. 


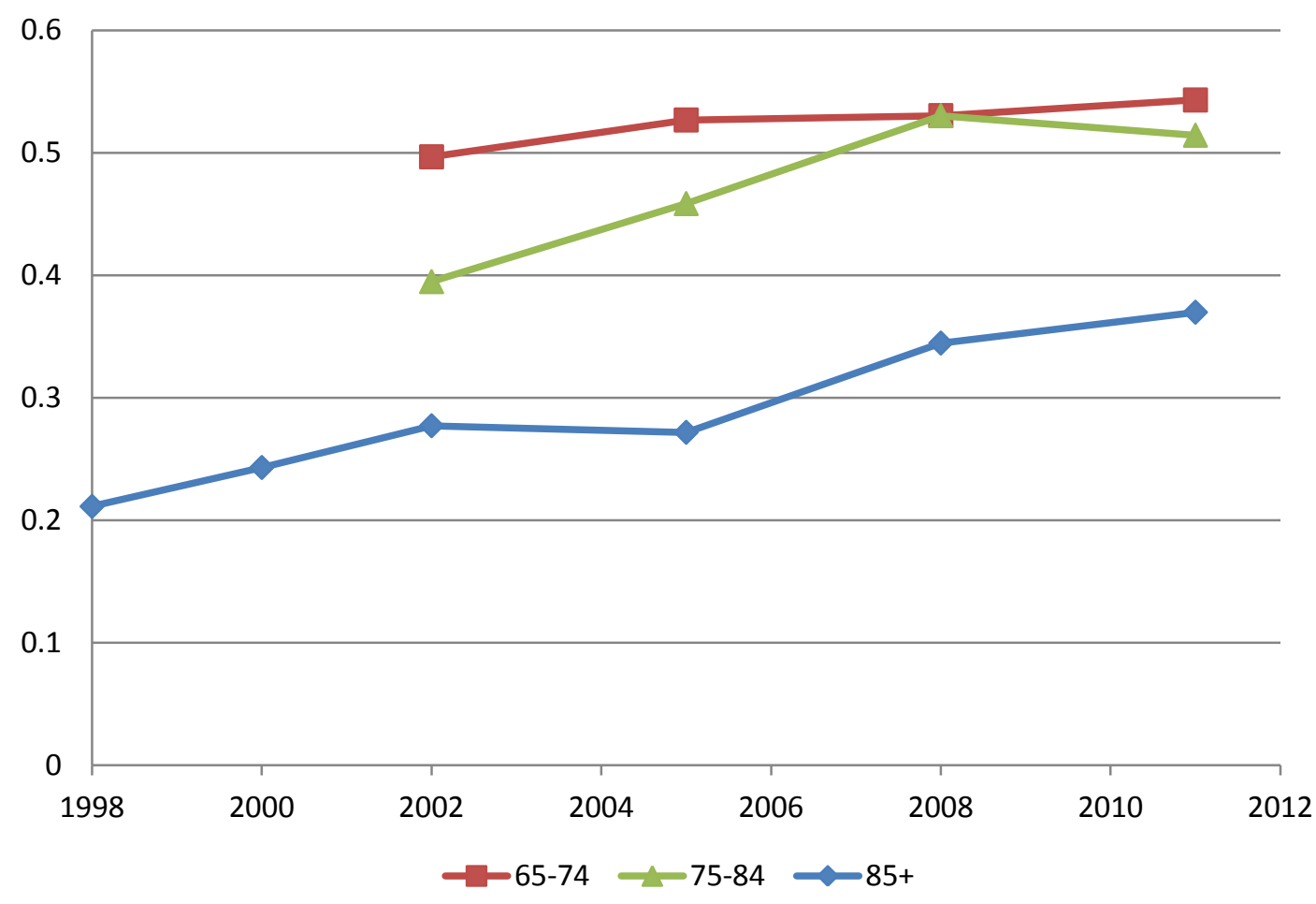

\section{Figure 1}

Fraction of Elderly Living Independently in Rural China (adjusted for sampling weight) Source: the CLHLS from 1998 to 2011/12. 
Table 1 Descriptive Statistics

\begin{tabular}{|c|c|c|c|c|c|}
\hline & \multirow{2}{*}{ Full sample } & \multicolumn{2}{|c|}{ Wave 2008/09 (pre-reform) } & \multicolumn{2}{|c|}{ Wave 2011/12 (post-reform) } \\
\hline & & Treated & Control & Treated & Control \\
\hline Sample Size & 3652 & 419 & 1407 & 419 & 1407 \\
\hline \multirow[t]{2}{*}{ Independent living } & 0.528 & 0.518 & 0.550 & 0.527 & 0.509 \\
\hline & $(0.499)$ & $(0.500)$ & $(0.498)$ & $(0.500)$ & $(0.500)$ \\
\hline \multirow[t]{2}{*}{ Monthly pension income (yuan) } & 12.575 & 0.000 & 0.000 & $129.735^{*}$ & 0.000 \\
\hline & $(68.608)$ & $(0.000)$ & $(0.000)$ & $(182.881)$ & $(0.000)$ \\
\hline \multirow[t]{2}{*}{ Age } & 74.773 & 73.494 & 73.148 & 76.604 & 76.235 \\
\hline & $(5.159)$ & $(4.957)$ & $(4.908)$ & $(4.927)$ & $(4.924)$ \\
\hline \multirow[t]{2}{*}{ Male } & 0.489 & 0.506 & 0.483 & 0.506 & 0.483 \\
\hline & $(0.500)$ & $(0.501)$ & $(0.500)$ & $(0.501)$ & $(0.500)$ \\
\hline \multirow[t]{2}{*}{ Han } & 0.919 & $0.964 * * *$ & 0.906 & $0.964 * * *$ & 0.906 \\
\hline & $(0.273)$ & $(0.186)$ & $(0.293)$ & $(0.186)$ & $(0.293)$ \\
\hline \multirow[t]{2}{*}{ Married } & 0.569 & 0.599 & 0.595 & 0.570 & 0.533 \\
\hline & $(0.495)$ & $(0.491)$ & $(0.491)$ & $(0.496)$ & $(0.499)$ \\
\hline \multirow[t]{2}{*}{ Years of schooling } & 2.170 & 2.284 & 2.190 & 2.193 & 2.102 \\
\hline & $(2.886)$ & $(2.822)$ & (2.923) & $(2.828)$ & $(2.883)$ \\
\hline \multirow[t]{2}{*}{ Economically independent } & 0.324 & 0.394 & 0.371 & 0.251 & 0.277 \\
\hline & $(0.468)$ & $(0.489)$ & $(0.483)$ & $(0.434)$ & $(0.448)$ \\
\hline \multirow[t]{2}{*}{ Owns an apartment } & 0.581 & 0.654 & 0.633 & 0.531 & 0.523 \\
\hline & $(0.493)$ & $(0.476)$ & $(0.482)$ & $(0.500)$ & $(0.500)$ \\
\hline \multirow[t]{2}{*}{ Had a white-collar job before age 60} & 0.016 & $0.026^{*}$ & 0.014 & $0.026 *$ & 0.014 \\
\hline & $(0.127)$ & $(0.160)$ & $(0.116)$ & $(0.160)$ & $(0.116)$ \\
\hline \multirow[t]{2}{*}{ Number of living children } & 4.280 & 4.341 & 4.278 & 4.295 & 4.259 \\
\hline & (1.607) & (1.574) & $(1.622)$ & $(1.566)$ & $(1.617)$ \\
\hline \multirow[t]{2}{*}{ No IADL limitation } & 0.619 & 0.714 & 0.697 & $0.575^{*}$ & 0.526 \\
\hline & $(0.486)$ & $(0.453)$ & $(0.460)$ & $(0.495)$ & $(0.500)$ \\
\hline \multirow[t]{2}{*}{ MMSE score } & 26.389 & 26.790 & 26.923 & 26.005 & 25.851 \\
\hline & $(5.169)$ & $(4.873)$ & $(4.427)$ & $(5.811)$ & $(5.659)$ \\
\hline \multirow{2}{*}{$\begin{array}{l}\text { Program duration in the county } \\
\text { (months) }\end{array}$} & 4.400 & 0.000 & 0.000 & $16.341 * * *$ & 6.553 \\
\hline & $(7.915)$ & $(0.000)$ & $(0.000)$ & (9.943) & $(7.810)$ \\
\hline
\end{tabular}

Note: $t$-test was applied for pairwise comparisons of the treated and control groups in each wave. *** $p<0.01$, ** $p<0.05, * p<0.1$. 
Table 2 Estimation for the NRPS Enrollment Decision and Pension Income

\begin{tabular}{|c|c|c|c|c|}
\hline \multirow[t]{3}{*}{ Dependent variable } & \multicolumn{2}{|c|}{ Enrollment in the NRPS } & \multicolumn{2}{|c|}{$\ln ($ pension income) } \\
\hline & $\begin{array}{c}\text { OLS using wave } \\
2011 / 12 \\
\end{array}$ & $\begin{array}{c}\text { FE using panel } \\
2008 / 09-2011 / 12\end{array}$ & $\begin{array}{c}\text { OLS using } \\
\text { wave } 2011 / 12 \\
\end{array}$ & $\begin{array}{c}\text { FE using panel } \\
2008 / 09-20011 / 12\end{array}$ \\
\hline & $(1)$ & $(2)$ & (3) & $(4)$ \\
\hline \multirow{2}{*}{$\begin{array}{l}\text { Program duration in the } \\
\text { county (months) }\end{array}$} & $0.024 * * *$ & $0.021 * * *$ & $0.112 * * *$ & $0.094 * * *$ \\
\hline & $(0.001)$ & $(0.001)$ & $(0.006)$ & $(0.005)$ \\
\hline \multirow[t]{2}{*}{ Age } & -0.008 & $-0.104 *$ & -0.196 & $-0.460 * *$ \\
\hline & $(0.060)$ & $(0.053)$ & $(0.258)$ & $(0.228)$ \\
\hline \multirow[t]{2}{*}{ Age squared/100 } & 0.007 & $0.054 *$ & 0.132 & 0.140 \\
\hline & $(0.039)$ & $(0.030)$ & $(0.169)$ & $(0.130)$ \\
\hline \multirow[t]{2}{*}{ Married } & 0.012 & 0.035 & 0.019 & 0.158 \\
\hline & $(0.020)$ & $(0.024)$ & $(0.090)$ & $(0.101)$ \\
\hline \multirow[t]{2}{*}{ Number of living children } & 0.003 & -0.029 & 0.014 & -0.092 \\
\hline & $(0.006)$ & $(0.026)$ & $(0.024)$ & $(0.100)$ \\
\hline \multirow[t]{2}{*}{ Economically independent } & -0.019 & -0.018 & -0.039 & -0.069 \\
\hline & $(0.022)$ & $(0.016)$ & $(0.102)$ & $(0.070)$ \\
\hline \multirow[t]{2}{*}{ Owns an apartment } & 0.003 & 0.012 & -0.009 & 0.059 \\
\hline & $(0.019)$ & $(0.015)$ & $(0.083)$ & $(0.065)$ \\
\hline \multirow[t]{2}{*}{ No IADL limitation } & $0.037 *$ & 0.004 & $0.171 * *$ & 0.041 \\
\hline & $(0.019)$ & $(0.016)$ & $(0.085)$ & $(0.071)$ \\
\hline \multirow[t]{2}{*}{ MMSE score } & -0.001 & -0.001 & -0.001 & -0.002 \\
\hline & $(0.002)$ & $(0.001)$ & $(0.006)$ & $(0.006)$ \\
\hline \multirow[t]{2}{*}{ Male } & 0.002 & & 0.003 & \\
\hline & $(0.020)$ & & $(0.089)$ & \\
\hline \multirow[t]{2}{*}{ Han } & 0.035 & & $0.152 *$ & \\
\hline & $(0.025)$ & & $(0.088)$ & \\
\hline \multirow{2}{*}{$\begin{array}{l}\text { Had a white-collar job before } \\
\quad \text { age } 60\end{array}$} & 0.056 & & 0.249 & \\
\hline & $(0.088)$ & & $(0.435)$ & \\
\hline \multirow[t]{2}{*}{ Years of Schooling } & 0.001 & & 0.008 & \\
\hline & $(0.003)$ & & $(0.016)$ & \\
\hline \multirow[t]{2}{*}{ Wave 2011} & & 0.124 & & $0.856^{* *}$ \\
\hline & & $(0.082)$ & & $(0.338)$ \\
\hline \multirow[t]{2}{*}{ Constant } & -0.271 & $4.848 *$ & 4.555 & $26.459 * *$ \\
\hline & $(2.284)$ & $(2.630)$ & $(9.837)$ & $(11.165)$ \\
\hline Province dummies & Yes & -- & Yes & -- \\
\hline Weak instrument test & $F=324.68 * * *$ & $\mathrm{~F}=429.71 * * *$ & $\mathrm{~F}=322.61 * * *$ & $\mathrm{~F}=394.80 * * *$ \\
\hline$R$-squared & 0.341 & 0.389 & 0.365 & 0.381 \\
\hline Number of observations & 1,554 & 3,580 & 1,498 & 3,511 \\
\hline
\end{tabular}

Note: Robust standard error are reported in parentheses in columns (1) and (3), and clustered-robust standard errors are reported in columns (2) and $(4)$; $^{*} p<0.10, * * p<0.05, * * * p<0.01$. 
Table 3 Effect of the NRPS on Independent Living for the Rural Elderly

\begin{tabular}{|c|c|c|c|c|c|}
\hline \multirow[t]{3}{*}{ Dependent variable: } & \multicolumn{5}{|c|}{ Independent living } \\
\hline & $\mathrm{FE}$ & $\mathrm{FE}$ & FE-IV & $\mathrm{FE}$ & FE-IV \\
\hline & (1) & (2) & (3) & (4) & $(5)$ \\
\hline $\begin{array}{l}\text { Program duration in the county } \\
\text { (months) }\end{array}$ & $\begin{array}{c}0.004 * * * \\
(0.001)\end{array}$ & & & & \\
\hline NRPS enrollment & & $\begin{array}{c}0.028 \\
(0.030)\end{array}$ & $\begin{array}{l}0.178 * * * \\
(0.069)\end{array}$ & & \\
\hline $\ln$ (pension income) & & & & $\begin{array}{c}0.001 \\
(0.007)\end{array}$ & $\begin{array}{c}0.041 * * * \\
(0.016)\end{array}$ \\
\hline Age & $\begin{array}{c}0.189 * * * \\
(0.072)\end{array}$ & $\begin{array}{c}0.205 * * * \\
(0.072)\end{array}$ & $\begin{array}{c}0.207 * * * \\
(0.072)\end{array}$ & $\begin{array}{c}0.226 * * * \\
(0.074)\end{array}$ & $\begin{array}{c}0.227 * * * \\
(0.075)\end{array}$ \\
\hline Age squared/100 & $\begin{array}{c}-0.137 * * * \\
(0.041)\end{array}$ & $\begin{array}{c}-0.141 * * * \\
(0.041)\end{array}$ & $\begin{array}{c}-0.146 * * * \\
(0.041)\end{array}$ & $\begin{array}{c}-0.152 * * * \\
(0.042)\end{array}$ & $\begin{array}{c}-0.155 * * * \\
(0.043)\end{array}$ \\
\hline Married & $\begin{array}{c}0.123 * * * \\
(0.038)\end{array}$ & $\begin{array}{c}0.126 * * * \\
(0.038)\end{array}$ & $\begin{array}{c}0.117 * * * \\
(0.038)\end{array}$ & $\begin{array}{c}0.129 * * * \\
(0.038)\end{array}$ & $\begin{array}{l}0.119 * * * \\
(0.039)\end{array}$ \\
\hline Number of living children & $\begin{array}{l}-0.014 \\
(0.035)\end{array}$ & $\begin{array}{l}-0.016 \\
(0.035)\end{array}$ & $\begin{array}{l}-0.009 \\
(0.035)\end{array}$ & $\begin{array}{l}-0.015 \\
(0.036)\end{array}$ & $\begin{array}{l}-0.009 \\
(0.036)\end{array}$ \\
\hline Economically independent & $\begin{array}{c}0.011 \\
(0.024)\end{array}$ & $\begin{array}{c}0.009 \\
(0.024)\end{array}$ & $\begin{array}{c}0.014 \\
(0.024)\end{array}$ & $\begin{array}{c}0.012 \\
(0.025)\end{array}$ & $\begin{array}{c}0.018 \\
(0.025)\end{array}$ \\
\hline Owns an apartment & $\begin{array}{c}0.194 * * * \\
(0.024)\end{array}$ & $\begin{array}{c}0.190 * * * \\
(0.024)\end{array}$ & $\begin{array}{c}0.192 * * * \\
(0.024)\end{array}$ & $\begin{array}{c}0.190 * * * \\
(0.025)\end{array}$ & $\begin{array}{c}0.192 * * * \\
(0.025)\end{array}$ \\
\hline No IADL limitation & $\begin{array}{c}0.021 \\
(0.021)\end{array}$ & $\begin{array}{c}0.023 \\
(0.021)\end{array}$ & $\begin{array}{c}0.020 \\
(0.021)\end{array}$ & $\begin{array}{c}0.023 \\
(0.022)\end{array}$ & $\begin{array}{c}0.019 \\
(0.022)\end{array}$ \\
\hline MMSE score & $\begin{array}{c}0.007 * * * \\
(0.002)\end{array}$ & $\begin{array}{c}0.008 * * * \\
(0.002)\end{array}$ & $\begin{array}{c}0.007 * * * \\
(0.002)\end{array}$ & $\begin{array}{c}0.007 * * * \\
(0.002)\end{array}$ & $\begin{array}{c}0.007 * * * \\
(0.002)\end{array}$ \\
\hline Wave 2011 & $\begin{array}{c}0.031 \\
(0.111)\end{array}$ & $\begin{array}{c}0.023 \\
(0.111)\end{array}$ & $\begin{array}{c}0.008 \\
(0.111)\end{array}$ & $\begin{array}{c}0.011 \\
(0.116)\end{array}$ & $\begin{array}{l}-0.016 \\
(0.115)\end{array}$ \\
\hline Constant & $\begin{array}{c}-6.240 * \\
(3.532) \\
\end{array}$ & $\begin{array}{c}-7.248 * * \\
(3.525) \\
\end{array}$ & & $\begin{array}{c}-8.184 * * \\
(3.658) \\
\end{array}$ & \\
\hline$R$-squared & 0.078 & 0.075 & 0.061 & 0.076 & 0.058 \\
\hline Number of observations & 3,556 & 3,556 & 3,520 & 3,489 & 3,386 \\
\hline
\end{tabular}

Note: Clustered-robust standard errors are reported in parentheses; ${ }^{*} p<0.10, * * p<0.05, * * * p<0.01$. 
Table 4 Tests of the Validity of the Identification Assumption

\begin{tabular}{|c|c|c|c|c|}
\hline \multirow[t]{5}{*}{ Dependent variable: } & \multicolumn{4}{|c|}{ Independent living } \\
\hline & \multicolumn{2}{|c|}{$\begin{array}{l}\text { Retired sample with other types of } \\
\text { social pension }\end{array}$} & \multicolumn{2}{|c|}{$\begin{array}{c}\text { Target sample before the } \\
\text { introduction of NRPS }\end{array}$} \\
\hline & $2011 / 12$ & $2008 / 09-2011 / 12$ & $2008 / 09$ & $2005-2008 / 09$ \\
\hline & OLS & FE & OLS & FE \\
\hline & $(1)$ & $(2)$ & $(3)$ & (4) \\
\hline $\begin{array}{l}\text { Program duration in the } \\
\text { county }\end{array}$ & $\begin{array}{c}0.001 \\
(0.001)\end{array}$ & $\begin{array}{c}0.001 \\
(0.001)\end{array}$ & & \\
\hline $\begin{array}{l}\text { Indicator of } 2009-2010 \text { pilot } \\
\text { counties }\end{array}$ & & & $\begin{array}{l}-0.019 \\
(0.021)\end{array}$ & $\begin{array}{l}-0.033 \\
(0.023)\end{array}$ \\
\hline Age & $\begin{array}{c}0.168 \\
(0.163)\end{array}$ & $\begin{array}{c}0.050 \\
(0.132)\end{array}$ & $\begin{array}{c}0.127 * * * \\
(0.042)\end{array}$ & $\begin{array}{l}0.120 * \\
(0.064)\end{array}$ \\
\hline Age squared/100 & $\begin{array}{l}-0.107 \\
(0.107)\end{array}$ & $\begin{array}{l}-0.067 \\
(0.079)\end{array}$ & $\begin{array}{c}-0.080 * * * \\
(0.028)\end{array}$ & $\begin{array}{c}-0.094 * * \\
(0.038)\end{array}$ \\
\hline Married & $\begin{array}{l}0.171 * * * \\
(0.054)\end{array}$ & $\begin{array}{c}0.043 \\
(0.080)\end{array}$ & $\begin{array}{c}0.155^{* * * *} \\
(0.018)\end{array}$ & $\begin{array}{c}0.140 * * * \\
(0.034)\end{array}$ \\
\hline Number of living children & $\begin{array}{c}0.006 \\
(0.018)\end{array}$ & $\begin{array}{c}0.012 \\
(0.037)\end{array}$ & $\begin{array}{l}0.025 * * * \\
(0.005)\end{array}$ & $\begin{array}{c}0.017 \\
(0.012)\end{array}$ \\
\hline Economically independent & $\begin{array}{c}0.001 \\
(0.054)\end{array}$ & $\begin{array}{c}0.059 \\
(0.041)\end{array}$ & $\begin{array}{c}0.023 \\
(0.020)\end{array}$ & $\begin{array}{l}0.063 * * * \\
(0.023)\end{array}$ \\
\hline Owns an apartment & $\begin{array}{l}0.296 * * * \\
(0.054)\end{array}$ & $\begin{array}{l}0.182 * * * \\
(0.044)\end{array}$ & $\begin{array}{l}0.338 * * * \\
(0.018)\end{array}$ & $\begin{array}{l}0.206 * * * \\
(0.022)\end{array}$ \\
\hline No IADL limitation & $\begin{array}{c}-0.150 * * * \\
(0.055)\end{array}$ & $\begin{array}{c}-0.105^{* *} \\
(0.047)\end{array}$ & $\begin{array}{c}0.027 \\
(0.018)\end{array}$ & $\begin{array}{c}0.029 \\
(0.021)\end{array}$ \\
\hline MMSE score & $\begin{array}{c}0.001 \\
(0.006)\end{array}$ & $\begin{array}{c}0.017 * * * \\
(0.005)\end{array}$ & $\begin{array}{l}-0.001 \\
(0.001)\end{array}$ & $\begin{array}{c}0.001 \\
(0.002)\end{array}$ \\
\hline Male & $\begin{array}{l}-0.031 \\
(0.061)\end{array}$ & & $\begin{array}{l}-0.001 \\
(0.018)\end{array}$ & \\
\hline Han & $\begin{array}{l}0.121 \\
(0.162)\end{array}$ & & $\begin{array}{l}0.154 * * * \\
(0.031)\end{array}$ & \\
\hline $\begin{array}{l}\text { Had a white-collar job before } \\
\text { age } 60\end{array}$ & $\begin{array}{c}0.066 \\
(0.077)\end{array}$ & & $\begin{array}{l}-0.086 \\
(0.054)\end{array}$ & \\
\hline Years of Schooling & $\begin{array}{c}0.002 \\
(0.008)\end{array}$ & & $\begin{array}{l}-0.006 * \\
(0.003)\end{array}$ & \\
\hline Wave 2011 & & $\begin{array}{c}0.162 \\
(0.193)\end{array}$ & & $\begin{array}{l}0.135^{*} \\
(0.081)\end{array}$ \\
\hline Constant & $\begin{array}{l}-6.289 \\
(6.227)\end{array}$ & $\begin{array}{l}-0.122 \\
(6.281)\end{array}$ & $\begin{array}{c}-5.068 * * * \\
(1.562)\end{array}$ & $\begin{array}{l}-3.599 \\
(2.934)\end{array}$ \\
\hline Province dummies & Yes & -- & Yes & -- \\
\hline R-squared & 0.265 & 0.076 & 0.211 & 0.101 \\
\hline Observations & 398 & 948 & 3,260 & 3,912 \\
\hline
\end{tabular}

Note: Robust standard error are reported in parenthesis of column (1) and (3), and clustered-robust standard errors are reported in columns (2) and (4); * $p<0.10, * * p<0.05$, *** $p<0.01$. 
Table 5 Effects of the NRPS on Independent Living by Population Groups

\begin{tabular}{|c|c|c|c|c|c|}
\hline \multirow{3}{*}{ Data } & \multicolumn{2}{|c|}{ Estimate on NRPS enrollment } & \multicolumn{2}{|c|}{ Estimate on $\ln ($ pension income) } & \multirow{2}{*}{ [mean] } \\
\hline & FE & FE-IV & FE & FE-IV & \\
\hline & (1) & $(2)$ & (3) & (4) & $(5)$ \\
\hline \multicolumn{6}{|c|}{ Panel 1. Subsamples by Presence of Nearby Children } \\
\hline Has children living nearby & $\begin{array}{c}0.052 \\
(0.032)\end{array}$ & $\begin{array}{c}\mathbf{0 . 2 1 3} * * * * \\
(0.067)\end{array}$ & $\begin{array}{c}0.007 \\
(0.008)\end{array}$ & $\begin{array}{c}\mathbf{0 . 0 4 9} * * * \\
(0.015)\end{array}$ & [0.479] \\
\hline Number of observations & 3,159 & 3,126 & 3,098 & 3,004 & \\
\hline Has no children living nearby & $\begin{array}{c}0.025 \\
(0.037)\end{array}$ & $\begin{array}{c}0.124 \\
(0.079)\end{array}$ & $\begin{array}{c}0.004 \\
(0.009)\end{array}$ & $\begin{array}{l}\mathbf{0 . 0 3 3} * \\
(0.018)\end{array}$ & [0.144] \\
\hline Number of observations & 1,923 & 1,908 & 1,885 & 1,832 & \\
\hline \multicolumn{6}{|c|}{ Panel 2. Subsamples by Economic Independence } \\
\hline Economically independent & $\begin{array}{c}0.024 \\
(0.049)\end{array}$ & $\begin{array}{c}\mathbf{0 . 3 0 9} * * * * \\
(0.114)\end{array}$ & $\begin{array}{l}-0.002 \\
(0.011)\end{array}$ & $\begin{array}{c}\mathbf{0 . 0 6 5} * * * \\
(0.025)\end{array}$ & [0.582] \\
\hline Number of observations & 1,337 & 1,322 & 1,317 & 1,282 & \\
\hline Economically dependent & $\begin{array}{c}0.026 \\
(0.038)\end{array}$ & $\begin{array}{c}0.068 \\
(0.086)\end{array}$ & $\begin{array}{c}0.001 \\
(0.009)\end{array}$ & $\begin{array}{c}0.017 \\
(0.020)\end{array}$ & [0.519] \\
\hline Number of observations & 2,219 & 2,198 & 2,172 & 2,104 & \\
\hline \multicolumn{6}{|c|}{ Panel 3. Subsamples by Homeownership } \\
\hline House owner & $\begin{array}{c}0.024 \\
(0.037)\end{array}$ & $\begin{array}{c}\mathbf{0 . 2 4 0} * * \\
(0.096)\end{array}$ & $\begin{array}{c}0.002 \\
(0.009)\end{array}$ & $\begin{array}{c}\mathbf{0 . 0 5 0} * * \\
(0.021)\end{array}$ & [0.667] \\
\hline Number of observations & 2,262 & 2,236 & 2,220 & 2,152 & \\
\hline Not house owner & $\begin{array}{c}0.026 \\
(0.050)\end{array}$ & $\begin{array}{c}0.091 \\
(0.093)\end{array}$ & $\begin{array}{l}-0.002 \\
(0.012)\end{array}$ & $\begin{array}{c}0.026 \\
(0.022)\end{array}$ & [0.325] \\
\hline Number of observations & 1,294 & 1,284 & 1,269 & 1,234 & \\
\hline \multicolumn{6}{|l|}{ Panel 4. Subsamples by Education } \\
\hline Educated & $\begin{array}{c}0.055 \\
(0.044)\end{array}$ & $\begin{array}{c}\mathbf{0 . 3 8 0} * * * * \\
(0.105)\end{array}$ & $\begin{array}{c}0.007 \\
(0.011)\end{array}$ & $\begin{array}{c}\mathbf{0 . 0 8 5} * * * \\
(0.024)\end{array}$ & [0.543] \\
\hline Number of observations & 1,702 & 1,682 & 1,668 & 1,614 & \\
\hline Illiterate & $\begin{array}{c}0.004 \\
(0.040)\end{array}$ & $\begin{array}{l}-0.005 \\
(0.094)\end{array}$ & $\begin{array}{l}-0.005 \\
(0.010)\end{array}$ & $\begin{array}{c}0.000 \\
(0.022)\end{array}$ & [0.543] \\
\hline Number of observations & 1,848 & 1,832 & 1,815 & 1,766 & \\
\hline \multicolumn{6}{|c|}{ Panel 5. Subsamples by Marital Status } \\
\hline Married & $\begin{array}{c}0.006 \\
(0.039)\end{array}$ & $\begin{array}{c}\mathbf{0 . 2 0 1} * * \\
(0.099)\end{array}$ & $\begin{array}{l}-0.005 \\
(0.009)\end{array}$ & $\begin{array}{c}\mathbf{0 . 0 4 4} * * \\
(0.022)\end{array}$ & [0.618] \\
\hline Number of observations & 2,151 & 2,132 & 2,113 & 2,056 & \\
\hline Widowed & $\begin{array}{c}0.061 \\
(0.047)\end{array}$ & $\begin{array}{c}0.143 \\
(0.090)\end{array}$ & $\begin{array}{c}0.008 \\
(0.011)\end{array}$ & $\begin{array}{c}0.034 \\
(0.021)\end{array}$ & [0.432] \\
\hline Number of observations & 1,405 & 1,388 & 1,376 & 1,330 & \\
\hline \multicolumn{6}{|c|}{ Panel 6. Subsamples by Health Status } \\
\hline No IADL limitation & $\begin{array}{c}0.032 \\
(0.037)\end{array}$ & $\begin{array}{c}\mathbf{0 . 2 6 6} * * * \\
(0.083)\end{array}$ & $\begin{array}{c}0.003 \\
(0.009)\end{array}$ & $\begin{array}{c}\mathbf{0 . 0 6 0} * * * \\
(0.018)\end{array}$ & [0.556] \\
\hline Number of observations & 2,493 & 2,470 & 2,448 & 2,380 & \\
\hline Have IADL limitation & $\begin{array}{l}-0.001 \\
(0.049)\end{array}$ & $\begin{array}{l}-0.018 \\
(0.122)\end{array}$ & $\begin{array}{l}-0.011 \\
(0.012)\end{array}$ & $\begin{array}{l}-0.007 \\
(0.029)\end{array}$ & [0.512] \\
\hline Number of observations & 1,063 & 1,050 & 1,041 & 1,006 & \\
\hline
\end{tabular}

Note:

(a) Cluster-robust standard errors are reported in parentheses; * $p<0.10$, ** $p<0.05$, *** $p<0.01$.

(b) Other control variables include age; age squared/100; marital status; number of living children; indicators of being economically independent, owning an apartment, and no IADL limitation; MMSE score; and a wave dummy.

(c) Baseline sample means of independent living for each subgroup are reported in the square brackets. 
Table 6 Effect of the NRPS on Independent Living for the Deceased Sample

\begin{tabular}{|c|c|c|c|c|}
\hline \multirow{3}{*}{ Dependent variable: } & \multicolumn{4}{|c|}{ Independent living } \\
\hline & OLS & 2 SLS & OLS & 2SLS \\
\hline & (1) & (2) & (3) & (4) \\
\hline \multirow[t]{2}{*}{ NRPS enrollment in last year of life } & -0.039 & 0.213 & & \\
\hline & $(0.077)$ & $(0.422)$ & & \\
\hline \multirow[t]{2}{*}{ ln (pension income) in last year of life } & & & -0.004 & 0.042 \\
\hline & & & $(0.017)$ & $(0.099)$ \\
\hline \multirow[t]{2}{*}{ Age in last year of life } & 0.090 & 0.080 & 0.095 & 0.090 \\
\hline & $(0.139)$ & $(0.134)$ & $(0.139)$ & $(0.133)$ \\
\hline \multirow[t]{2}{*}{ Age squared/100 } & -0.061 & -0.053 & -0.064 & -0.059 \\
\hline & $(0.089)$ & $(0.086)$ & $(0.089)$ & $(0.085)$ \\
\hline \multirow[t]{2}{*}{ Married in last year of life } & $0.207 * * *$ & $0.206 * * *$ & $0.209 * * *$ & $0.210 * * *$ \\
\hline & $(0.050)$ & $(0.049)$ & $(0.050)$ & $(0.049)$ \\
\hline \multirow{2}{*}{$\begin{array}{l}\text { Economically independent in last year } \\
\text { of life }\end{array}$} & $0.138^{*}$ & 0.125 & $0.134 *$ & 0.121 \\
\hline & $(0.080)$ & $(0.082)$ & $(0.080)$ & $(0.084)$ \\
\hline \multirow[t]{2}{*}{ No ADL limitation in last year of life } & 0.087 & $0.090^{*}$ & 0.085 & 0.087 \\
\hline & $(0.054)$ & $(0.053)$ & $(0.054)$ & $(0.053)$ \\
\hline \multirow[t]{2}{*}{ MMSE score in wave 2008} & -0.001 & -0.001 & -0.001 & -0.001 \\
\hline & $(0.003)$ & $(0.003)$ & $(0.003)$ & $(0.003)$ \\
\hline \multirow[t]{2}{*}{ Number of living children in wave 2008} & 0.011 & 0.011 & 0.011 & 0.010 \\
\hline & $(0.013)$ & $(0.012)$ & $(0.013)$ & $(0.013)$ \\
\hline \multirow[t]{2}{*}{ Owns an apartment in wave 2008} & $0.146 * * *$ & $0.148 * * *$ & $0.148 * * *$ & $0.151 * * *$ \\
\hline & $(0.050)$ & $(0.049)$ & $(0.050)$ & $(0.049)$ \\
\hline \multirow[t]{2}{*}{ Male } & 0.019 & 0.009 & 0.018 & 0.013 \\
\hline & $(0.050)$ & $(0.052)$ & $(0.050)$ & $(0.050)$ \\
\hline \multirow[t]{2}{*}{ Han } & 0.139 & 0.139 & 0.139 & 0.141 \\
\hline & $(0.090)$ & $(0.086)$ & $(0.090)$ & $(0.086)$ \\
\hline \multirow[t]{2}{*}{ Had a white-collar job before age 60} & 0.073 & 0.093 & 0.071 & 0.087 \\
\hline & $(0.170)$ & $(0.165)$ & $(0.170)$ & $(0.165)$ \\
\hline \multirow[t]{2}{*}{ Years of schooling } & -0.011 & -0.010 & -0.012 & -0.011 \\
\hline & $(0.010)$ & $(0.010)$ & $(0.010)$ & $(0.010)$ \\
\hline \multirow[t]{2}{*}{ Constant } & -3.533 & -3.374 & -3.758 & -3.767 \\
\hline & $(5.417)$ & (5.196) & (5.404) & $(5.157)$ \\
\hline Province dummies & Yes & Yes & Yes & Yes \\
\hline$R$-squared & 0.195 & 0.177 & 0.194 & 0.180 \\
\hline Number of observations & 467 & 467 & 465 & 465 \\
\hline
\end{tabular}

Note: Robust standard errors are reported in parentheses; * $p<0.10, * * p<0.05$, *** $p<0.01$. 
Table 7 Difference between the Attrited and Non-Attrited Samples

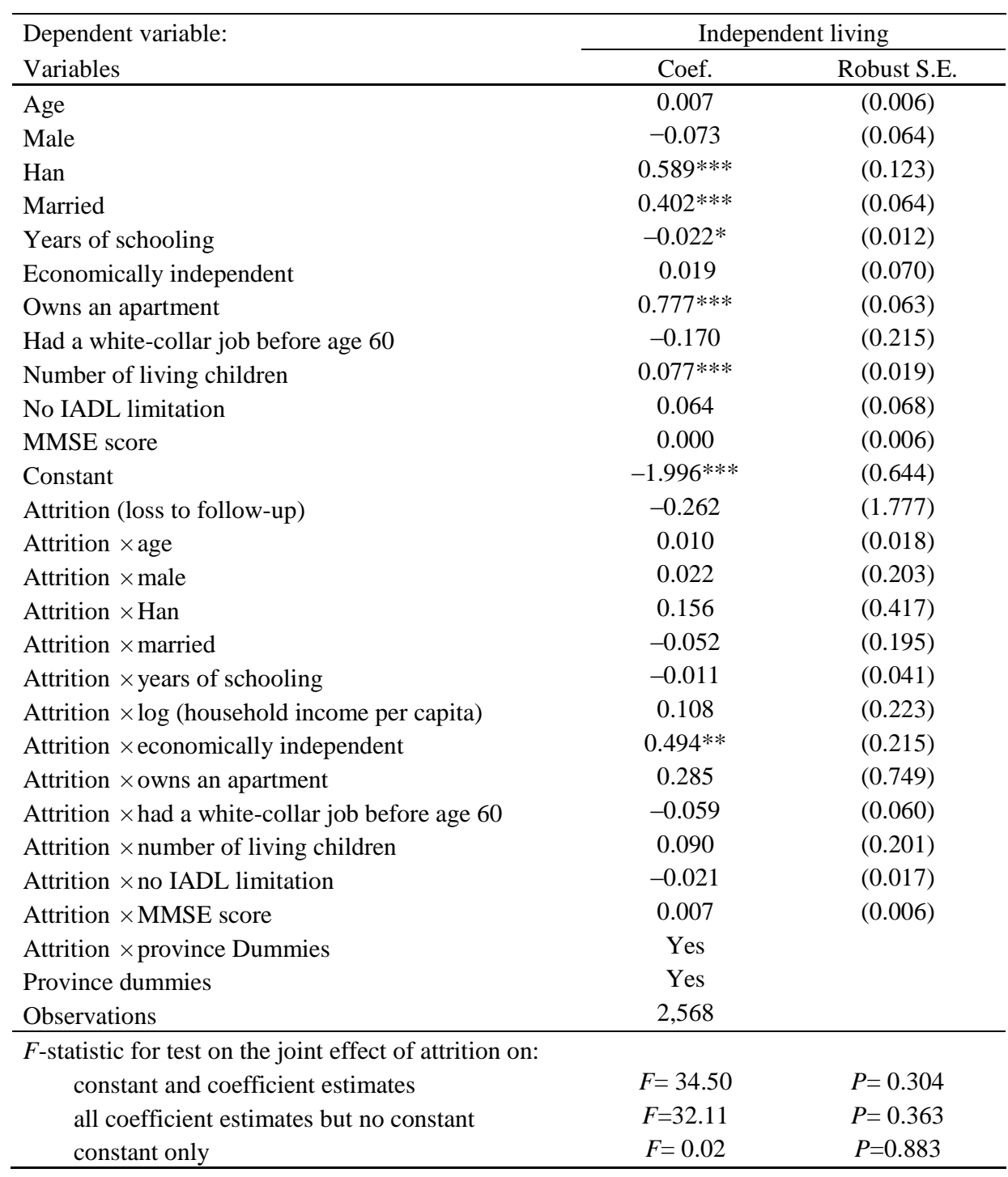

Note: Robust standard errors are reported in parentheses; $* p<0.10$, ** $p<0.05$, *** $p<0.01$. 


\section{APPENDIX}

Table A1 Number of respondents

\begin{tabular}{lcc}
\hline Main analysis & $\begin{array}{c}\text { Number } \\
\text { Excluded }\end{array}$ & $\begin{array}{c}\text { Number } \\
\text { remaining }\end{array}$ \\
\hline CLHLS 2008 & 13341 & 16552 \\
Restrict to rural respondents aged 65-84 & $\mathbf{3 2 1 1}$ \\
Exclude respondents with missing values for social pension & 88 & 3123 \\
Exclude respondents with any other types of social pension & 476 & 2647 \\
Exclude respondents residing in elderly centers or nursing homes & $\mathbf{2 0}$ & $\mathbf{2 6 2 7}$ \\
\hline Respondents lost to follow-up in 2011/12 survey & & $\mathbf{3 1 6}$ \\
Respondents deceased before 2011/12 survey & & $\mathbf{4 8 5}$ \\
$\quad$ Participated in NRPS & & $40(8.25 \%)$ \\
$\quad$ Did not participate in NRPS & & $445(91.75 \%)$ \\
Respondents reinterviewed in 2011/12 survey & & $\mathbf{1 8 2 6}$ \\
$\quad$ Participated in NRPS & & $419(22.95 \%)$ \\
$\quad$ Did not participate in NRPS & $1407(77.05 \%)$ \\
\hline
\end{tabular}


Table A2 Effect of the NRPS on Independent Living for the Oldest-Old

\begin{tabular}{lccccc}
\hline \multirow{2}{*}{\begin{tabular}{l} 
Dependent variable: \\
\multirow{2}{*}{ Data }
\end{tabular}} & \multicolumn{2}{c}{ NRPS enrollment } & \multicolumn{3}{c}{ Pension income } \\
\cline { 2 - 5 } & FE & FE-IV & FE & FE-IV & [mean] \\
\cline { 2 - 5 } & $(1)$ & $(2)$ & $(4)$ & $(5)$ & $(6)$ \\
\hline The oldest-old (age 85 and above) & -0.022 & -0.036 & -0.008 & -0.011 & {$[0.304]$} \\
& $(0.023)$ & $(0.055)$ & $(0.005)$ & $(0.012)$ & \\
Number of observations & 3,599 & 3,542 & 3,533 & 3,410 & \\
& & & & & \\
The oldest-old with no IADL limitation & 0.018 & 0.003 & 0.005 & 0.009 & {$[0.440]$} \\
Number of observations & $(0.063)$ & $(0.145)$ & $(0.015)$ & $(0.031)$ & \\
& 539 & 532 & 533 & 520 & \\
The oldest-old with IADL limitation & -0.029 & -0.048 & $-0.011 *$ & -0.017 & {$[0.280]$} \\
Number of observations & $(0.025)$ & $(0.059)$ & $(0.006)$ & $(0.013)$ & \\
\hline
\end{tabular}

\section{Note:}

(a) Cluster-robust standard errors are reported in parentheses; $* p<0.10$, ** $p<0.05$, *** $p<0.01$.

(b) Other control variables include age; age squared/100; marital status; number of living children; indicators of being economically independent, owning an apartment, and no IADL limitation; MMSE score; and a wave dummy.

(c) Baseline sample means of independent living for each subgroup are reported in square brackets. 
Table A3 2008/09 characteristics by attrition status in 2011/12

\begin{tabular}{|c|c|c|c|c|c|c|}
\hline \multirow{3}{*}{$\begin{array}{l}\text { The elderly sample in wave } \\
\qquad 2008 / 09\end{array}$} & \multirow{3}{*}{$\begin{array}{c}\begin{array}{c}\text { Full } \\
\text { sample } \\
N=2627\end{array} \\
(1)\end{array}$} & \multirow{3}{*}{$\begin{array}{c}\begin{array}{c}\text { Attritors } \\
\mathrm{N}=316\end{array} \\
(2)\end{array}$} & \multicolumn{3}{|c|}{ Non-Attritors } & \multirow{3}{*}{$\begin{array}{l}\text { Diff. } \\
\text { (3)-(2) }\end{array}$} \\
\hline & & & \multirow{2}{*}{$\begin{array}{c}\begin{array}{c}\text { All } \\
\mathrm{N}=2311\end{array} \\
(3)\end{array}$} & \multirow{2}{*}{$\begin{array}{c}\text { Alive } \\
\mathrm{N}=1826 \\
(4)\end{array}$} & \multirow{2}{*}{$\begin{array}{c}\begin{array}{c}\text { Deceased } \\
\mathrm{N}=485\end{array} \\
(5)\end{array}$} & \\
\hline & & & & & & \\
\hline Independent living & $\begin{array}{c}0.516 \\
(0.500)\end{array}$ & $\begin{array}{c}0.567 \\
(0.496)\end{array}$ & $\begin{array}{c}0.509 \\
(0.500)\end{array}$ & $\begin{array}{c}0.543 \\
(0.498)\end{array}$ & $\begin{array}{c}0.381 \\
(0.486)\end{array}$ & $-0.058^{*}$ \\
\hline Age & $\begin{array}{l}74.413 \\
(5.452)\end{array}$ & $\begin{array}{l}75.149 \\
(6.238)\end{array}$ & $\begin{array}{l}74.313 \\
(5.329)\end{array}$ & $\begin{array}{l}73.227 \\
(4.920)\end{array}$ & $\begin{array}{l}78.400 \\
(4.804)\end{array}$ & $-0.836 * *$ \\
\hline Male & $\begin{array}{c}0.498 \\
(0.500)\end{array}$ & $\begin{array}{c}0.472 \\
(0.500)\end{array}$ & $\begin{array}{c}0.502 \\
(0.500)\end{array}$ & $\begin{array}{c}0.489 \\
(0.500)\end{array}$ & $\begin{array}{c}0.553 \\
(0.498)\end{array}$ & 0.030 \\
\hline Han & $\begin{array}{c}0.923 \\
(0.267)\end{array}$ & $\begin{array}{c}0.943 \\
(0.232)\end{array}$ & $\begin{array}{c}0.920 \\
(0.271)\end{array}$ & $\begin{array}{c}0.919 \\
(0.273)\end{array}$ & $\begin{array}{c}0.924 \\
(0.266)\end{array}$ & -0.023 \\
\hline Married & $\begin{array}{c}0.562 \\
(0.496)\end{array}$ & $\begin{array}{c}0.525 \\
(0.500)\end{array}$ & $\begin{array}{c}0.567 \\
(0.496)\end{array}$ & $\begin{array}{c}0.596 \\
(0.491)\end{array}$ & $\begin{array}{c}0.460 \\
(0.499)\end{array}$ & 0.042 \\
\hline Years of schooling & $\begin{array}{c}2.074 \\
(2.840)\end{array}$ & $\begin{array}{c}1.838 \\
(2.733)\end{array}$ & $\begin{array}{c}2.106 \\
(2.853)\end{array}$ & $\begin{array}{c}2.212 \\
(2.900)\end{array}$ & $\begin{array}{c}1.709 \\
(2.635)\end{array}$ & 0.268 \\
\hline Economically independent & $\begin{array}{c}0.335 \\
(0.472)\end{array}$ & $\begin{array}{c}0.367 \\
(0.483)\end{array}$ & $\begin{array}{c}0.331 \\
(0.471)\end{array}$ & $\begin{array}{c}0.376 \\
(0.485)\end{array}$ & $\begin{array}{c}0.159 \\
(0.366)\end{array}$ & -0.037 \\
\hline Owns an apartment & $\begin{array}{c}0.608 \\
(0.488)\end{array}$ & $\begin{array}{c}0.655 \\
(0.476)\end{array}$ & $\begin{array}{c}0.602 \\
(0.490)\end{array}$ & $\begin{array}{c}0.638 \\
(0.481)\end{array}$ & $\begin{array}{c}0.466 \\
(0.499)\end{array}$ & $-0.054^{*}$ \\
\hline $\begin{array}{l}\text { Had a white-collar job before } \\
\quad \text { age } 60\end{array}$ & $\begin{array}{c}0.017 \\
(0.130)\end{array}$ & $\begin{array}{c}0.019 \\
(0.137)\end{array}$ & $\begin{array}{c}0.017 \\
(0.129)\end{array}$ & $\begin{array}{c}0.016 \\
(0.127)\end{array}$ & $\begin{array}{c}0.019 \\
(0.135)\end{array}$ & -0.002 \\
\hline Number of living children & $\begin{array}{c}4.253 \\
(1.627)\end{array}$ & $\begin{array}{c}4.065 \\
(1.652)\end{array}$ & $\begin{array}{c}4.279 \\
(1.622)\end{array}$ & $\begin{array}{c}4.293 \\
(1.611)\end{array}$ & $\begin{array}{c}4.228 \\
(1.664)\end{array}$ & $0.214 * *$ \\
\hline No IADL limitation & $\begin{array}{c}0.625 \\
(0.484)\end{array}$ & $\begin{array}{c}0.563 \\
(0.497)\end{array}$ & $\begin{array}{c}0.634 \\
(0.482)\end{array}$ & $\begin{array}{c}0.700 \\
(0.458)\end{array}$ & $\begin{array}{c}0.384 \\
(0.487)\end{array}$ & $0.071 * *$ \\
\hline MMSE Score & $\begin{array}{l}26.083 \\
(5.725)\end{array}$ & $\begin{array}{l}26.146 \\
(5.552)\end{array}$ & $\begin{array}{l}26.074 \\
(5.750)\end{array}$ & $\begin{array}{l}26.892 \\
(4.533)\end{array}$ & $\begin{array}{l}22.996 \\
(8.264)\end{array}$ & -0.071 \\
\hline
\end{tabular}

Note: $t$-test was applied to test the significance of the difference. $* * * p<0.01, * * p<0.05, * p<0.1$. 